\title{
DAPPER DUDES: AN EXPLORATION OF YOUNG MEN'S FASHION CONSUMPTION AND CONCEPTIONS OF MASCULINITY
}

by

Dylan Martin, B.A. Communication, Toronto, May 9, 2014

An MRP presented to Ryerson University

in partial fulfillment of the

requirements for the degree of

Master of Arts

in the Program of

Fashion

Toronto, Ontario, Canada, 2014

(C) (Dylan Martin) 2014 
DAPPER DUDES

\section{Author's Declaration For Electronic Submission of a MRP}

I hereby declare that I am the sole author of this MRP. This is a true copy of the MRP, including any required final revisions.

I authorize Ryerson University to lend this MRP to other institutions or individuals for the purpose of scholarly research

I further authorize Ryerson University to reproduce this MRP by photocopying or by other means, in total or in part, at the request of other institutions or individuals for the purpose of scholarly research.

I understand that my MRP may be made electronically available to the public. 


\begin{abstract}
If sensationalized media reports are any indication, the men's fashion industry has entered into an exciting phase of expansion and evolution. As the market diversifies to become increasingly vibrant and varied, prominent ready-to-wear labels continue to showcase evermore divergent and gender-blurring designs in what is celebrated as an anything-goes period in menswear. To examine whether these clothing trends and industry transitions have lasting real world implications, this research seeks to give voice to fashion-conscious male consumers - the subject of scarce qualitative scholarship. Insights gleaned from 20 in-depth interviews with young Canadian men point to contemporary shifts not only in shopping habits and tastes, but also in hegemonic masculinity. Responding to romantic assertions that there are "no rules" in twenty-first century fashion, findings examine the extent to which long withstanding Western menswear conventions prevail. Through illuminating the lived experiences of sartorially savvy males aged 19 to 29, this study uncovers how Generation Y men navigate gender norms and expectations while crafting an idiosyncratic sense of style. Ultimately, this research enriches existing industry and theoretical understandings of how young men approach fashion.
\end{abstract}

Keywords: men's fashion, hegemonic masculinity, gender norms 


\section{Acknowledgements}

Special thanks to my advisor Dr. Ben Barry for his invaluable mentorship and support.

I would also like to thank the stylish men who were kind enough to volunteer their time to enrich this thesis project with their candid insights. These young sartorialists

beautifully illustrate that men with curious minds and creative spirits can create truly powerful messages through their clothing. 
DAPPER DUDES

\section{Table of Contents}

List of Figures

Chapter 1: Introduction $\quad$ 1-3

Chapter 2: Research Context 4-16

Masculinity as Performance 4-6

The Inverted Male Gaze $\quad 6-7$

Men's Dress Across Place and Time 8-11

The 1980s Establishment of Modern Men's Fashion 11-13

The Metrosexual as Contemporary Prototype 13-14

Experimental Menswear 15-16

Chapter 3: Methodology $\quad$ 17-20

Data Collection $\quad 17-18$

Data Analysis $\quad 18-19$

Locating Myself $\quad 19-20$

Chapter 4: Findings

Idiosyncratic Style and Identity 21-30

$\begin{array}{ll}\text { Creative Limitations } & 30-41\end{array}$

Men's Fashion Progressions $\quad$ 42-55

Chapter 5: Discussion 56-62

$\begin{array}{lr}\text { Future Research Opportunities } & 60\end{array}$

Industry Implications $\quad 61$

$\begin{array}{lr}\text { Conclusion } & 61-62\end{array}$

Appendices

References 
DAPPER DUDES

\section{List of Appendices}

\section{Appendix A}

Research Participant Sample Information 63-64 
DAPPER DUDES

\section{Introduction}

As the twenty-first century progresses young males are becoming more mindful of the way they dress and present themselves. This emerging demographic of fashionably aware consumers is reported to be spending more of their earnings and energy on menswear. They are also beginning to openly participate in fashion as both a leisure activity and creative pursuit (Bakewell, Mitchell \& Rothwell, 2006). Growing interest in men's apparel and appearance management have given the contemporary menswear market momentum, outpacing the growth rate of the highly saturated women's wear industry by almost double (Rees, 2012). Furthermore, an increasingly diverse number of fashion initiatives are aiming to reach the underserved young male consumer base, with e-commerce proving to be just one segment of the men's industry undergoing significant market expansion (Young, 2012). Acknowledging the lucrative potential of Generation Y fashion consumers, recent business reports have started to identify these men by the neologism yummy or young urban male (Dudoff, 2014; Stock, 2014). As Business Week has snidely suggested, "Luxury fashion may be switching gender and age roles. In much of the world now, the most attractive demographic for such companies as Burberry and Coach isn't middle-aged women with sky-high credit limits; it's twenty-something men with smartphones and self-esteem issues" (Stock, 2014).

This research aims to explore these market transitions from a social and cultural perspective, uncovering why men are becoming more avid and informed fashion consumers; it also addresses what these market changes suggest about contemporary conceptions of masculinity and gender performance. Bringing together queer theory, 


\section{DAPPER DUDES}

masculinities and gender studies approaches, this research is guided by the following inquiries: 1) What inspires Generation Y men to become interested in fashion and physical presentation? 2) How do conceptions of gender and sexuality affect sartorial choices? 3) In what ways does our current cultural climate restrict and/or encourage men to participate in fashion and use clothing as a means of self-expression? Through documenting the existing challenges and opportunities young men encounter when actively engaging in fashion, research brings everyday dress concerns to the forefront. These observations come together to suggest what men's fashion consumption might say about modern understandings of masculinity.

This research aims to fill a gap in knowledge as few academics have empirically examined the attitudes and behaviours of male fashion consumers. It is of value to listen first-hand to how style conscious men relate and respond to the menswear that is marketed to them. This study is an answer to Tim Edwards' call for “... more qualitative research that actually listens to men as not only the primary markers of masculinity but also its primary consumers..." (2006, p.163). The seminal masculinities studies scholar has suggests that in the spirit of second wave feminism it would be fruitful for fashion research to give voice to men and document their experiences through qualitative analysis (Edwards, 2006). It is of interest to consider how young consumers engage in personal style and dress in daily life, as social stigmas surrounding fashion-obsessed males persist. Even within the realm of academia it can be difficult to glean men's fashion consumer research participants because, as Kaiser identifies, “....many men often do not feel comfortable participating in a study on "men's fashion." At least initially, they often feel more interested in, or accepting of, the study when we use a more neutral term such as 
DAPPER DUDES

“menswear" (which is less marked)" (2012, p.125). This research has included a breadth of men — both heterosexual and homosexual — who actively read fashion media and are passionate about menswear. In doing so, this study further debunks the misperception that males are largely uninterested in clothing and physical presentation (Craik, 1994;

Edwards, 1997). It encourages more capacious ways of thinking about fashionable men.

This research first gives an overview of existing studies that address consumer culture and fashion through a masculinities studies lens. It offers both a historical and contemporary overview of how men have engaged in fashion and notions of masculinity to illustrate their complex and culturally dependent relationship. Research then describes the qualitative methodology implemented and reveals findings deduced from 20 in-depth interviews. These insights shed light on the inspirations and motivations behind Generation Y male clothing choices. This study then offers academic implications and concludes by arguing it would be advantageous for additional research to explore men's fashion consumption across a variety of participant ages and cultures. 
DAPPER DUDES

\section{Research Context}

\section{Masculinity as Performance}

Taking a masculinities studies theoretical approach, this research works to examine gender and sexuality identity issues from the perspective of male fashion consumers. Critically examining men's fashion in this way enables scholars to denaturalize the gendered associations one's culture has imparted on garments and question masculine/ feminine binaries used to distinguish styles of dress (Entwistle, 2000). Reflecting on these theoretical concepts, Edwards has argued “... masculinity is essentially constructionist: it is assumed that there is no universal or natural foundation to masculinity... (because it is) contingent upon individual and social interpretation” (1997, p. 4). Despite being an inherently fluid construct, men are constantly evaluated on a set of normative masculine appearances and demeanors (Connell, 2005; Forth, 2008). These standards comprise hegemonic masculinity, a process that involves the continual subordination of culturally 'lesser' modes of looking and acting like a man (Connell, Messerschmidt, 2005). The power of these hierarchical ideals is evident when reflecting on "... the entrenched and durable nature of certain dominant images of manhood in Western culture.” (Forth, 2008, p. 231). Through exploring notions of hegemonic masculinity, one can begin to uncover why men seek to emulate and exude 'manly' physical and stylistic qualities and also how they affirm and/or destabilize these ideals through the medium of fashion.

Related gender and queer studies understandings of performativity are also helpful when reflecting on the motivations behind men's sartorial selections. Similarly to 


\section{DAPPER DUDES}

hegemonic masculinity, gender norms are deeply engrained and socially enforced. And so, we perform gender (Butler, 1990) through a series of actions and behaviours including fashion consumption and body management. As feminist theorists have suggested, gender is a “... proscription and a task; in effect, gender is a norm that we struggle to embody” (Salih, 2004, p. 26). Just as 'becoming' a woman involves a purposive and appropriative set of acts, as Beauvoir has famously observed, 'becoming' a man arguably requires a similar series of strategic choices (Salih, 2004). When recognizing that categories such as sex, gender and sexuality are not self-evident, one can begin to see the arbitrariness behind gendered fashion variances (Kirby, 2006). To clarify these arguments, Kaiser (2012) draws on feminist biological scientist Fausto-Sterling who notes gender is not a hardwired entity "...(she) points to the need to understand gender as "softly assembled" in a complex articulation of the body, time, psychology, and cultural space" (2012, p.124). In this way, fashion has the ability to help define and redefine gender boundaries, as gender is culturally constructed - it is not inevitable or the result of biology and destiny (Edwards, 2006; Entwistle, 2000).

As distinctions between menswear and women's wear are thought to be blurring, and more men have expressed an open interest in clothing, it is of interest to reflect on how masculinity is shifting forms. Negrin's work Appearance and Identity (2008) is a helpful reference point as the scholar convincingly argues hegemonic masculinity, and associated gender norms, continually reassert themselves despite increasing gender border crossings in contemporary fashion. The scholar challenges Baudrillard's postmodern assertion that masculine/ feminine signifiers are now adopted freely by all genders. Contrarily, Negrin (2008) argues prevailing gender boundaries have not 


\section{DAPPER DUDES}

disappeared but merely been renegotiated under new terms. Furthermore, while avantgarde style magazines continually combine masculine and feminine signifiers together in a visually impactful way, “...ultimately what is presented is a variant of masculinity rather than a transcendence of it (Negrin, 2008, p 158). Lipovsky (1994) strengthens these arguments, noting fashionable styles continue to incorporate differentiating signs into garments, as menswear colours, cuts and fits are still typically different then women's wear. Additionally, it continues to be much more common for women's dress to borrow gender symbols from men's dress then vice versa. Paoletti and Brush Kidwell (1989) have proposed that this could, in part, be because masculine symbols are more highly valued. It might also be because hegemonic masculinity remains more narrowly defined, and plagued by lingering homophobic sentiments, then hegemonic femininity.

\section{The Inverted Male Gaze}

While men still risk being ridiculed for taking pleasure in shopping and related practices, contradictorily hegemonic masculinity has begun to increasingly include fashion consumption within its modern definition. The industry's relatively recent focus on male consumers has seemed to alter understandings of masculinity, which is increasingly constructed as part of consumer society and a matter of appearances (Edwards, 2011). Moreover, masculinity has emerged as a lucrative marketing and retailing strategy. For instance, memes of American historical masculine icons like the Ivy Leaguer, the jock and the blue-collar worker are repetitively used to sell authenticity and heritage to prospective shoppers (Matthews, Hancock \& Gu, 2013). In this way, idealized male figures are advertised and sold to male consumers in a compelling way. 


\section{DAPPER DUDES}

And so, while fashion consumption has often been regarded as the antithesis of hegemonic masculinity, it has ironically become of instrumental importance in shaping and defining the concept.

As Edward's (1997) work entitled Men in the Mirror implies, male consumers are made to focus on their physical selves, both scrutinizing and narcissistically admiring their appearances. The scholar suggests men are increasingly evaluated on personal style and body care, arguing that masculinity is evermore wrapped up in self-styling and performance (2006). As Patterson and Elliott (2002) propose, contemporary men's fashion has actually "inverted" the male gaze; these researchers note that young men are now viewing their own bodies as sites of identity management. While apparent gender role blurring has sparked discomfort in many conservatively inclined consumers, Ervin (2011) has observed shifting power dynamics as more and more men are being "looked at" and not necessarily "doing the looking." This process confuses and inverts active/passive, male/female binaries (Ervin, 2011). Kimmel and Tissier-Desbordes make a similar suggestion: “...where once women were the subject and men the surveyors (and appraisers) of appearance, the playing field has become just as political for men - but now men are also a spectacle to everyone, including themselves" (1999, p. xvii). As Luciano (2011) has noted, fashion consumption has also become part of "the quintessential male strategy" to achieve and display stereotypically masculine goals such as career success and power. In an increasingly media and image driven culture "...masculinity is no longer simply an essence or an issue of what you do, it's how you look" (Edwards, 1997, p. 55). 
DAPPER DUDES

\section{Men's Dress Across Place and Time}

While this research investigates how modern day men participate in fashion on an individual and personal basis, it is beneficial to reflect on historic academic explorations of men's appearance management and dress. By doing so, men's long withstanding relationship with fashion is revealed; moreover, the role of social and cultural context in underpinning men's dress habits is highlighted. These accounts help explain how contemporary dress conventions and hegemonic masculine ideals came into fruition. This overview demonstrates that what is deemed appropriate men's attire is ever changing, as hegemonic masculinity constantly reconfigures itself to remain dominant.

Anthropological and historical studies of men's dress are a beneficial reference point as they suggest that attitudes towards gender, sexuality and masculinity are largely dependent on one's setting. For instance, Craik (1993) argues that in many non-Western societies body decoration is as much a male as a female pursuit, as demonstrated by New Guinea and Austrian Aboriginals among myriad of other cultures. Buchbinder has similarly highlighted how masculinity is " ... culturally specific and historically considered" (2013, p. 5). Buchbinder provides the example of the Wodaabe people of West Africa as one of many examples of how different cultures understand masculinity and gender relations. These nomadic people hold an annual weeklong celebration where men traditionally paint their faces and decorate their bodies, accentuating their best features to impress potential female mates; “....within Wodaabe culture, the capacity of a young man to attract the attention of an eligible partner through his physical beauty and his ability to dance both is a sign of his masculinity and, at the same time, in part constitutes that masculinity" (Buchbinder, 2013, p. 5). While many Western men 


\section{DAPPER DUDES}

similarly participate in 'peacocking' to attract sexual and romantic attention, it is apparent that this is not a modern phenomenon. These examples suggest men's dress and adornment have a rich and varied history, playing an integral role in many cultural practices and traditions.

As scholars have documented, even within Western culture, subsets of men have historically expressed open interest in fashion and donned an array of stylish garments. Polhemus (2000) points to the $18^{\text {th }}$ century Rococo as an example of a time when the meanings behind fashion signifiers dramatically shifted, as flamboyant and conventionally 'feminine' frilly dress aesthetics, white wigs and facial cosmetics represented prestige and privilege. The elaborateness of aristocratic ensembles were optimized by European Macaronis and Fops who wore ostentatiously ornate and grandiose garments to distinguish themselves from the growing bourgeoisie (Arnold, 2001; Craik, 1992). While these exaggerated characters were later dismissed as flippant and feminine through the $19^{\text {th }}$ century 'Great Masculine Renunciation' (Flugal, 1930), they demonstrate that male respectability and power are not naturally connected to a restrained and streamlined dress aesthetic, but have merely been culturally constructed in this way.

Beyond being influenced by democratic post-Revolutionary attitudes, 'the Great Masculine Renunciation' was also thought to be a result of European imperialists wanting to embody their supposed "rational" and "civilized" superiority over "primitive" colonized cultures. Somber dress codes were implemented to distance Western men from non-Western dress and body decoration traditions (Polhemus, 2000, p.46). The Renunciation had gender implications, too, and was utilized to distinguish "appropriate" 


\section{DAPPER DUDES}

male and female performativities. As the world progressed with the Industrial Revolution, gender roles became even more divided - as upper class women were confined to the home and put on display to convey social and economic status - while men sported durable and demure outfits they could work in (Entwistle, 2000; Veblen, 1953). Interestingly, while slightly modified and modernized, conventional men's styles have remained largely the same, mainly the suit, which continues to act as an international dress standard connoting Western manliness and professionalism (Hollander, 1994; Kaiser, 2012).

It is important to note that while the 'Great Masculine Renunciation' introduced austere ideals of work and equality into men's dress, a number of scholars have rejected Flugal's assertion that the period offered total uniformity (Barthes, 2006). Breward (1999) argues against perceptions that the $19^{\text {th }}$ century Western male became completely separated from concerns relating to fashion and decoration. The scholar points to the importance of nuances in men's dress details, as wealthy men and refined fashion figures such 'the dandy' worked to subtly distinguish themselves. "Since it was no longer possible to change the basic type of clothing for men without affecting the democratic and work ethos, it was the detail...the 'je ne sais quois'... which started to play the distinguishing role in clothing: the knot on a cravat, the material of a shirt, the buttons on

a waistcoat, the buckle on a shoe, were from then on enough to highlight the narrowest of social differences" (Barthes, 2006, p. 66). What Barthes and Breward have astutely observed is that while men's fashion became more subdued with the 'Great Masculine Renunciation,' many men continued to treat their clothing with consciousness and care. These principles largely remain today, as subtle forms of dress distinction often mark 
DAPPER DUDES

status and taste for men. Barthes and Breward's observations also point to the fact that men's constrained dress options don't necessarily suggest male consumers are less preoccupied with the way they present themselves, it merely means the outfits they wear are typically less varied.

\section{The 1980s Establishment of Modern Men's Fashion}

While men have long approached physical presentation with thoughtfulness and consideration, it wasn't until the 1980s that they were deemed a lucrative consumer base to strategically market high fashion and luxury goods to. It was in this decade menswear was first introduced to the international fashion week circuit with famed designers like Giorgio Armani and Calvin Klein. The 1980s was also a time when lifestyle magazines like $G Q$ achieved notoriety, leading to the rise of men's fashion experts and intermediaries (Edwards, 2011; Mort, 1996). To coincide with the expansion of a series of interrelated men's fashion, grooming, and media initiatives, a new style- and bodyconscious male consumer emerged. Marketing 'experts' identified the intriguing figure as the new man, a precursor to what was later known as the metrosexual. This fashionable male figure was defined by his participation in rigorous physical fitness, his acceptance of equality in domestic life, and his narcissistic preoccupation with personal appearances (Edwards, 2011). The new man is of significance as his “...relationship to clothing and adornment presented a sharp contrast to the no-nonsense 'wash and go' masculinity, which has dominated much of the nineteenth and twentieth centuries (Entwistle, 2000, p.146). With these changes, Edwards $(1997 ; 2011)$ argues male desirability became increasingly a matter of appearance management and shopping choices. 


\section{DAPPER DUDES}

The 1980s marked a pivotal moment in men's fashion for reasons beyond the establishment of high fashion menswear collections and the well-cultured new man. While scholars have typically addressed early men's lifestyle magazines uniformly, the 1980s actually saw the development of a range of fashion-related media content — these publications lay the groundwork for the dynamic way young men understand personal style today. As Crewe points out, "Too often in journalistic accounts of the period, the men's magazine market was discussed as a monolithic entity. It does not do justice to the different values and cultures expressed across the sector...”(2003, p.194). While much of the existing research on 1980s men's fashion focuses on large publications like the rebranded American $G Q$, 'style press' targeted at both young men and women like $i-D$ and now defunct Blitz and The Face also emerged. These magazines encouraged readers to develop and assemble a unique personal aesthetic (Mort, 1996). Through the rhetoric of individualism "...the manufacture of the self is promoted as an exercise of individual creativity" (Negrin, 2008, p. 18). As Mort (1996) notes, the importance of the style press wasn't in quantitative readership numbers, but in their ability to celebrate consumption and youth culture in way that excited and unified creative young people in the aftermath of 1970s punk. Provocative stylists like Ray Petri and photographers like Herb Ritts displayed their work in style press, juxtaposing race, class, gender and sexuality signifiers within the alluring editorials they created (Arnold, 2001). These bold bricoleurs incorporated elements of urban athletic wear with Native American iconography, bourgeoisie women's jewellery, classic cowboy clothing and more (Logan, 2000).

Ultimately the proliferation of 1980s subcultural movements helped give credibility to style press and their romantic proclamations that readers could invent their 


\section{DAPPER DUDES}

own trends, as opposed to following those established by industry elites. These individualistic dress aesthetics were deemed more authentic and real, as they emerged from cool and creative young people on the streets (Mort, 1996; Negrin, 2008). They endorsed fearless fashion and free expression as a newfound approach to menswear and masculinity. And so, as Mort has observed, the array of 1980s marketing and media efforts that targeted men "...produced a plurality of masculinities, many of which have rubbed against each other in tensions of antagonism. Differences of economic power and status, of generation, regional positioning, sexuality and ethnicity, have all contributed to this contested pluralism" (1996, p. 206). Ultimately, while sexualized muscular men and streamlined European suits were perpetually promoted as the ideal form of masculinity, alternative aesthetics were available through unconventional style magazines. These early accounts of men's fashion and lifestyle content are relevant as they point to the contemporary media landscape in which men have a diverse variety of fashion aesthetics to choose from. Male consumers are evermore encouraged to express individuality and personality through dress.

\section{The Metrosexual as Contemporary Prototype}

Alongside the 1980s new man, the early 2000s metrosexual is a helpful reference point when researching fashionable men today. As they were identified as a straight male demographic interested in fashionable goods and grooming products, the metrosexual indicates a turning point in perceptions of heterosexual/ homosexual and male/ female fashion consumption distinctions. Sender's (2006) analysis of Queer Eye for the Straight Guy reveals these supposed changes in consumption patterns. The scholar smartly 


\section{DAPPER DUDES}

suggests that the makeover series' humour comes from its ability to poke fun of the idea that through appearance management and consumption, “...now straight white guys have to work harder, in the ways women and gay men have had to work, in order to get and keep their mate, their job, and their class position" (2006, p.146).

Ervin (2011) interestingly proposes that while the metrosexual may have started out as a marketing ploy faced by affluent Caucasian males like David Beckham, 'he' strangely has the potential to subversively challenge what masculinity means to consumers. The scholar suggests it was unsurprising the metrosexual received substantial media attention and provoked reactionary responses; the fashionable figure both did and did not 'act straight' which made some people feel uneasy as heterosexuality and homosexuality weren't presented as polarities but across a spectrum (Ervin, 2011). In this way, societal panic often ensues when gender is defined in fluid rather than fixed terms, and is regarded as contingent rather than natural (Ervin, 2011). Ultimately, though, backlash against the 'feminine' characteristics and leisure pursuits of the metrosexual have further advanced the idea of there being a multiplicity of ways to perform masculinity. Anti-metrosexual sentiments that suggested consumers act and behave "like real men," inadvertently shed like on the fact masculinity is just another version of drag, retrosexuality, as defined by Ervin (2011). In the end, it seems that increasingly since the metrosexual figure, and as the $21^{\text {st }}$ century has progressed, consumers have been offered an expanding range of styles to assemble individualistically. Arguably, masculinity is also culturally understood in increasingly non-specific and relativistic terms. 


\section{DAPPER DUDES}

\section{Experimental Menswear}

While the contemporary menswear market is said to include a growing selection of bright and bold fashionable styles (Davies, 2008), the reality is young men are often still fearful of being thought of as "too feminine" (Kimmel, 1994). Exploring issues of masculinity and men's fashion, several scholars have correspondingly suggested that males are more likely to experiment with sartorial statements that defy hegemonic masculinity when in 'safe' spaces that encourage creative dress. For instance, Carreño (2014) turns to designer Marc Jacobs as a case study, examining a transparent Comme des Garçons black lace tunic he wore over white boxer short to the 2012 Gala at the Metropolitan Museum's Costume Institute. While Jacobs' outfit was a provocative mix of a number of dress styles, gender identities and cultural signifiers, Carreño emphasizes, “...it is important to bear in mind that this transgression occurred within the context of the red carpet at the Met Gala, an event specifically intended to showcase extreme fashion. In this sense Jacobs's flouting of dress codes was calculated in that it was performed within the safe and artificial environment of the red carpet..." (2014, p. 63).

Similarly addressing the relationship between one's environment and willingness to experiment with creative dress, Green's (2009) study Somewhere in Between: Transformative Spaces, Shifting Masculinities, and Community Style offers insights into the dreamy, drug-induced bohemia of Burning Man, where men allow themselves to indulge in the euphoria of totally experimental and out-there fashion. Within this accepting space, Green (2009) notes that limitations of hegemonic masculinity are loosened and men are encouraged to experiment with clothing and appearance, without fear of social stigma or the "othering gaze" of the community around them. Green (2009) 
DAPPER DUDES

notes some Burning Man participants found it difficult to integrate back into the critical and sartorially limited societies they came from. And so, Green (2009) highlights how a man's environment can stifle and/or stimulate creative dress.

Related to these examples, Bancroft $(2012 ; 2013)$ observes that—despite avantgarde designers' efforts to establish new and innovative ways of thinking about gender, femininity and masculinity - these runways shows and fashion events typically operate within 'a space set to the side' meaning their 'real world' implications are difficult to determine. The scholar offers an important observation: while conceptual designers might present utopian post-gender runway collections, the critical audience that appreciates these expressive and androgynous looks is limited. Many consumers continue to show discomfort and dislike for styles that fall outside of steadfast masculine dress conventions (Bancroft, 2013). Drawing on these studies, this research focuses on how men with trendoriented and/or statement-making idiosyncratic personal styles are received in 'realword' and 'everyday situations.' 
DAPPER DUDES

\section{Methodology}

A phenomenological qualitative methodology was employed for this study in order to illuminate how young men approach fashion from a subjective and personal perspective (Creswell, 2007). The purposive sample (Kuzel, 1992) was comprised of 20 Canadian men who represented a broad a diverse range of personal style aesthetics, occupational and educational backgrounds, body sizes, ethnicities and sexualities (See Figure 1 for Participant Sample Information). Furthermore, research focused specifically on 19 to 29 year olds. It is beneficial to explore the consumer attitudes of males in this age cohort to further assess existing research findings that suggest " “...Generation $\mathrm{Y}$ males have been socialised by mass media and marketing activities to a greater extent them previous generations... to view fashion in a more positive light..." (Bakewell, Mitchell \& Rothwell, 2006, p.170). This research study compliments Bakewell, Mitchell and Rothwell's (2006) quantitative survey of Generation Y consumers, offering first person insights and experiences to enrich understandings of how this young demographic engage with concepts of fashion and masculinity.

\section{Data Collection}

All prospective participants were asked to confirm that they self identified as a 'fashion enthusiast' and read at least 1 men's fashion-related blog a month. This requirement helped ensure that all potential interviewees were actively interested and aware of contemporary fashion attitudes and trends. Participants were first recruited from the researcher's social and professional network. After identifying and interviewing 


\section{DAPPER DUDES}

several men with relevant characteristics, a snowballing sampling strategy was used-as interviewees were asked for the names of friends and peers with shared interests in personal style. By asking initial participants for referrals of additional young male fashion followers, the researcher was able to reach out to a broad network of like-minded men (Kawamura, 2011).

Each interview took place on a university campus or predetermined public library meeting room in the cities of Toronto and Vancouver, Canada. Semi-structured interviews were conducted following a checklist of questions and themes for the researcher to address in a conversational manner (Kawamura, 2011). These open-ended discussions were structured to make participants in the study feel comfortable and open to detail their dress routines and honestly comment on potentially sensitive issues pertaining to fashion, gender and sexuality. The interviewees' willingness to stay engaged in one-on-one interviews for extended durations, and reveal personal thoughts and experiences, reflected the researcher's attempt to create a relaxed and friendly environment (Kawamura, 2011). These interviews were audio-recorded and transcribed for analysis.

\section{Data Analysis}

Analysis of transcriptions followed the qualitative strategy of data reduction, data display, and conclusion drawing/verification (Miles \& Huberman, 1994). Through an iterative process, transcriptions were firstly coded with descriptive labels to categorize data. While continually comparing and contrasting data, the researcher wrote memos and noted similarities and connections between interviews. Initial categories were grouped 


\section{DAPPER DUDES}

according to major themes relating to a) gender b) sexuality c) masculinity and d) lifestyle. Throughout the analysis, the researcher visually mapped out and organized information according to the developing relationships observed between interviewee responses (Miles \& Huberman, 1994). After 20 interviews were completed, clear patterns emerged and conclusions become increasingly grounded and explicit — as the point theoretical saturation had been reached (Miles \& Huberman, 1994).

\section{Locating Myself}

While outlining the research methodology, it is pertinent to locate myself, as the primary researcher within the process. Acknowledging the importance of approaching empirical research self-reflexively, it is relevant to note that I entered this study from the perspective of a queer Caucasian male with an academic background in fashion history and theory. Having long turned to fashion to nostalgically escape to the past, inject aesthetic interest into the present, and dream fantastically about the future, I ultimately have a strong emotional attachment to fashion and personal style. In turn, my background and beliefs have had an undeniable affect on this study. While an effort was made to maintain a level of interview professionalism, similarities between research participants and myself were evident, as both parties were avid fashion followers of the same age demographic. Commonalities between interviewer/interviewee have seemingly resulted in more open and candid conversation, as participants may have felt more comfortable to dispel personal stories to someone who likely understood and related to their experiences firsthand. Overall, through the interviews and data analysis, it was crucial to consistently remind myself of my person opinions and experiences relative to those discussed, 


\section{DAPPER DUDES}

consciously maintaining a critical distance to: a) ensure I did not ask leading questions, b) keep control of the interview process, c) accurately completed data analysis and findings as subjectively as possible. 
DAPPER DUDES

\section{Findings}

Analysis of interview transcriptions uncovered a series of creative challenges and opportunities that young male consumer's face while developing an individualistic sense of style. These observations are organized according to three major sections: 1 .

Idiosyncratic Style and Identity outlines how young men have positively responded to contemporary menswear rhetoric, which celebrates a unique and personal approach to dress. 2. Creative Limitations details factors holding men back from cultivating their ideal aesthetic. 3. Men's Fashion Progressions points to shifts in the menswear industry and broader cultural landscape that have motivated males to engage with fashion.

\section{Idiosyncratic Style and Identity}

This first section addresses how interviewees expressed themselves through style and physical presentation. Participants noted that they pursued fashion as a means of displaying their identity and sense of creativity (as explored in 1.1 and 1.2). Through their sartorial choices they aligned themselves with urban life and neo-tribes of young people inspired by similar music and nightlife scenes (these subjects are elaborated on in

\section{3 and 1.4).}

\subsection{Pursuing Uniqueness in Dress}

Illustrating how men's fashion styles have become more individualistically focused, research participants emphasized that they had very particular and personal intentions behind their fashion statements. They felt that they had distinctive points of 


\section{DAPPER DUDES}

view, which were reflected in the way they dressed and presented themselves. As Interviewee 2 suggested, "I think we inherently all want to make a mark... They always say fashion is a language, so in that sense it's a way to be seen and heard by people you cross paths with." Interviewee 9 similarly noted, "I really like fashion because it kind of helps define me and people are able to see who I am before they're actually able to talk to me. It represents me." This linkage between style and identity was strong for many of the men, explaining why they strove to establish "a specific personal signature" as Interviewee 11 described it. This desire for uniqueness was recurrent amongst the majority of research participants. As interviewee 5 remarked, "I'd like to believe there is at least a little something unique about the way I put my clothes together... It's almost like there is a little bit of my DNA or my personal brand in there."

Many of research participants felt there was something special about their resourcefulness and styling abilities. They enjoyed collecting and assembling disparate elements to create a style they felt reflected who they were as people. As Interviewee 7 explained, "I try and put my personal stamp on things, like I'll tuck my dress shirt in only on one side so it's askew or I'll try and roll the sleeves up interestingly or knot a scarf unusually... it kind of shows you can think outside of the box..." This expression of difference and distinctiveness was seemingly at the forefront of most interviewee's minds when consuming clothing. As Interviewee 16 said, “... it's one thing to have impeccable taste but to me it's all about putting your own kind of flair in there... I don't want to be a fashion robot." Many other participants similarly prided themselves on stretching their creative muscles when putting together an ensemble. In this way, interviewees would seem to largely agree with Back's (1985) outlook on fashion. Production and 


\section{DAPPER DUDES}

consumption are regarded as complementary and cannot survive separately, as the consumer's arrangement of the final product becomes a creative occasion within itself and a continuation of an ongoing artistic process (Back, 1985).

Interviewees oftentimes suggested there was considerable care involved in getting ready for work or leisure situations. Some men referenced 'self-styling' as opposed to just 'dressing,' as one means of implying there was a level of skill or work involved. Participants explained that they made clothing selections with deliberate intension in mind, reflecting on their personal vision and aesthetic direction. As Interviewee 3 noted:

"There are actually people who go into stores and will take a plenty amount of time to decide this black shirt or this black shirt. Paying attention to texture and cut and fabrication, that kind of thing. I'm one of those people, and that's because I'm a creative kind of person.... you have to be like a curator who hand picks the perfect paintings for an exhibit... You try and find unique fashion pieces that draw you in and then you let bigger picture themes emerge... You then bring them together under your style."

While the majority of interviewees had a desire to create unique fashion statements, the young men had contrasting means of reaching sartorial individuality. Some of the research participants, who appreciated the refinement and restraint of traditional men's fashion, were passionate about playing with the nuances and detailing of menswear to distinguish themselves. For instance, Interviewee 16 concentrated on more subtle details like, “...statement socks, or no socks and cuffed trousers... It's this focus on unexpected little extras, like cool ties, lapel pins, pocket squares..." Some interviewees similarly suggested that they liked standing out in subtle yet surprising ways while working in traditional fields like business management. They articulated an interest in wearing blazer or suit ensembles with playfully designed cufflinks, ties, footwear, or even accent shoelaces; as Interviewee 10 proclaimed, “... it's a way to set 


\section{DAPPER DUDES}

myself apart in sea of suits..." These men prided themselves on looking put-together, suggesting that sharp tailoring and exceptional fitting garments were a sophisticated and understated way to set themselves apart.

Taking a more unconventional approach to menswear, other interviewees expressed an interest in sartorially standing out in more bold and colourful ways. As Interviewee 13 explained, 'I'm looking for colour, textures, patterns, something different... I don't like to look like everybody else." Some of these young men sought out trend-setting looks that actively challenged parameters of taste and acceptability. As Interviewee 5 joked, “...most fashionable things were once deemed ugly, so like it's good to push yourself if you want to be original... I think being on top of fashion and being creative is becoming more and more important for young people... It's about challenging yourself." A number of other interviewees similarly said they gravitated towards the unordinary —including saturated colours, untraditional menswear materials like silk or neoprene, graphic prints, and unabashedly cheeky sayings or imagery on their clothing. These men suggested that they liked looking for apparel with "attitude" to help reflect their personality.

Overall, these two approaches to fashion, as outlined by interviewees, are not incongruent. While some men focused sartorial efforts on subtle details and others were more concerned about the overall eye-catching effect of their ensembles, numerous interviewees expressed that their fashion interests were not definable or specific. These young men said that their style was ever changing and dependent on their mood, social setting, etc. Furthermore, regardless of whether interviewees reveled in the sleek simplicity of classic menswear or sought out the eccentric and over-the-top, they all 
DAPPER DUDES

expressed a desire to develop a sense of style that made a statement and was one-of-akind.

\subsection{Dress and Identity}

As interviewees elaborated on their style choices, they suggested that they not only strove to showcase their keen eye and sense of creativity, but also wanted to express deeper parts of their identity through dress and physical presentation. As Interviewee 1 disclosed:

'I'll wear my baggy pants tucked into my star socks and I'll be in a skin-tight top. That's part of my look at as contemporary dancer but I like to transition that style into my outside life, too...I kind of pride myself on being a weirder queer dude so I like to totally look the part, and I kind of combine that with the dance I do, the scene of people I hang out with... I feel the need to hit all those notes."

This account highlights how a man's creative endeavours, professional life, social circle and sexuality might coalesce and come to influence how he expresses himself through fashion.

Interviewee 3 similarly used dress to express his unique identity. Along with several other research participants, he felt it was important to showcase his cultural background and heritage through his clothing. He explained:

“... my mom, she's Fijian and Japanese and my dad is Cherokee Indian and African... My blood runs in so many different directions... because my ethnic background is so all over the place I like to play with a lot of the different cultural styles and combine them in my own way. Is my style like authentically true to any one of the cultural styles? No, but like I put it all together in a way that makes sense to me."

These personal accounts prove that an individual's sense of style can have rich layers of meaning. These sartorial choices go beyond simply displaying class, gender and 


\section{DAPPER DUDES}

occupational distinctions — as were historically considered the primary functions of men's fashion (Entwistle, 2000).

Interviewees oftentimes sought out unusual, sometimes even obscure sources of fashion inspiration to help highlight their individuality - they offered colourful examples of how dynamic men's personal style and dress can be. For instance, Interviewee 3 explained that he turned to unique fashion references, such as the New York Club Kids of the late 1980s, to ensure he did not look "cookie-cutter." Also playing with creative stylistic ideas, Interviewee 1 explained he was inspired by, “... the video games that I used to play as a kid. I'm also into a lot of the subcultures in China. They have a lot of crazy hairdos and cool patterns... that work in a weird way.” Interviewee 6 was similarly satisfied with his idiosyncratic look, as he enjoyed wearing clothes hauntingly decorated in “... dark spiritual symbols like Ouija boards and all-seeing eyes and mandalas..." because he felt they offered a deeply individual approach that nicely reflected his attraction to dark romanticism. These personal stories indicate that young male consumers are willing to take their styles in increasingly unique directions.

\subsection{The Man-About-Town}

Beyond expressing individuality, interviewees felt as though their fashion statements suggested something about their identities as city dwellers. Numerous research participants drew connections between the fact that a) they were young, b) they lived in the city, c) they were fashionable, d) they were creatively and culturally plugged in. Through aligning with these identity traits, interviewees were able to defend their fashion choices and distinguish themselves from their critics. For instance, Interviewee 6 


\section{DAPPER DUDES}

proposed, “...you want to make sure that when you go out and walk to work, and meet your friends afterwards, that you look good. I feel like men are caring more and more because it's the culture of living in cities." It is of interest to note that as participants were gleaned from Toronto and Vancouver, many of the men were happy to identify themselves as the 'type' to frequent the city and live the accompanying lifestyle, which was thought to include caring about clothing. These ideals coincide with those outlined by Edwards (1997) who suggests contemporary consumer culture prioritizes and celebrates men who are not only wealthy and good-looking, but also well-located and young.

Overall, it seems that the interviewees were both inspired by and related to idealized depictions of the cosmopolitan man, as is perpetually presented in fashion media. They somewhat romantically suggested that the fashionable man of today is someone who is progressive, artistically inclined, and distinctly urban. Many of the research participants felt as though they were privileged to have grown up in environments that fostered idiosyncratic dressing. For instance, Interviewee 12 suspected that many men were not provided opportunities to enjoy the pleasurable qualities of men's apparel and shopping, “...I'd bet there's a lot of guys out there who really want to get into it, but probably don't because of their upbringing or because of the social circle that they're surrounded with... What's not to like about nice clothes and clothes that fit well and feel good?" While interviewees experienced their own set of creative limitations, the young men interviewed appreciated belonging to fashionable, forwardthinking communities and lifestyles. 
DAPPER DUDES

\subsection{Neo-Tribal Males}

When asked what motivated their sense of fashion, many research participants suggested they were drawn to styles loosely associated with larger creative and cultural groups or music scenes. While interviewees continuously drew connections between their personal style, their music tastes and 'scenes' of likeminded young people, they approached these affiliations in eclectic and enigmatic ways. Therefore, while participant's felt there were strong linkages between their style and music interests, they indicated these preferences were often pluralistic and shifting. As Interviewee 8 explained, "My style relates to the different circles of friends I have. Some of them are harder and edgier, like more aggressive, while others are more eccentric and queer... I play up my different sides of myself and my style depending on the occasion and the group..." In this way, Interviewees' experiences seemed to illustrate Maffesoli's concept of 'tribalism' or 'neo-tribalism' as defined by Bennett (1999). Interviewees did not typically identify with neatly classified subcultures, but with transient and informal groups with shared musical sensibilities, patterns of consumption, and clothing preferences.

Just as high fashion designers have continually appropriated and reinterpreted music genres and movements as a source of inspiration, interviewees suggested they did the same. Interviewees noted that psychedelic rock, underground hip-hop, grunge, goth, post-punk, indie electronica, queer dance music, rap, and rave culture were just some of their sources of style inspiration. Further demonstrating neo-tribal tendencies, Interviewee 6 cited British punk and soft grunge movements as sources of inspiration, noting “... my influences change over time, just like my music tastes are evolving, but I 


\section{DAPPER DUDES}

definitely look towards the musicians I respect for fashion inspiration.” These music interests were sometimes even the impetus behind their initial exploration of fashion and personal style. As Interviewee 12 noted:

"I got really into music and that's when I kind of got into fashion, and I think they definitely go hand-in-hand... when I was younger and I started to pursue music and DJing more seriously, that's when I started to become more aware and wanted to give off a certain aesthetic that kind of complemented what I was into playing..."

When discussing music and personal style many of the men brought up nightlife 'scenes' in their local cities, as this was where neo-tribal networks of young people seemed to assemble. As Interviewee 7 explained, “I get really into Toronto’s music scene, like there are certain bars and venues I tend to frequent... so of course my friends and I dress up for those kinds of events in a way that makes sense.” Furthermore, many of the young men suggested that they felt freest to explore their styles and commit to sartorial looks that made a statement when they went out to bars, clubs and dancehalls with like-minded people. For instance, Interviewee 12 explained how within his 'music scene,' his long lean body and penchant for all black Euro-fit ensembles were seen as attractive qualities, whereas they might have been the subject of ridicule elsewhere. Relatedly, Interviewee 3 joked:

"I can wear weird stuff and like unusual combinations with my scene of artistic gay friends. It's encouraged in that circle... We like to think we're a cool queer cult in Vancouver... there is a scene and a number of local events that are kind of alt and trashy and grungy and it suits us..."

Music scenes and the accompanying nightlife offered interviewees an environment to get inspired by their fashion forward peers and explore their personal sense of style. These spaces also sparked competitiveness amongst men, as Interviewee 12 admitted, “... going out definitely motivates you to step up you game a bit..." in order to feel attractive and 


\section{DAPPER DUDES}

popular. As these personal accounts indicate, many men expressed a desire to be looked at and to be the object of the gaze, as they not only wished to feel creatively relevant but sexually sought after.

Overall, interviewees pointed to a diverse range of lifestyles and neo-tribal networks they identified with, these were often fuelled by related art, music and youth culture affiliations. Participants focused on their personal style to both establish themselves as creative individuals but also connect with those with similar tastes and interests. As Interviewee 14: “... the way you want to look and dress in terms of fashion is probably quite similar to the way you want to travel, and the way you want to just generally live." In this way fashion can be seen as an integral part of the defining of young men's identities. It has also become an important way to development relationships and connections. For example Interviewee 13 explained how he made many lasting friendships through his love of sneaker culture and hip-hop music. Interviewees felt as though peer groups and creative avenues came together to help define who they were as individuals.

\section{Creative Limitations}

While interviewees were eager to express themselves through fashion, they also noted that they faced clothing criticism and scrutiny. Research participants often edited their ensembles; they felt the need to 'offset' colours, fabrics and prints that might be deemed feminine with styles that connoted masculinity (these ideas are outlined in 2.1 and 2.2.) Both heterosexual and homosexual interviewees spoke about being affected by expectations surrounding their gender and sexuality (as examined in 2.3 and 2.4). Finally, 
DAPPER DUDES

this section also explores how men continue to feel confined to long withstanding menswear norms, and believe women's fashion has had more of an opportunity to reach its creative potential (2.5).

\subsection{Fashion Policing}

Many of the interviewees noted that they had experienced varying levels of criticism or disapproval from friends, family and outsiders when their sartorial selections deviated from hegemonic masculine norms. Research participants actively scrutinized, edited, and reassembled their outfits, oftentimes to comply to larger social and cultural

pressures. For example, Interviewees 4 and 5-both nineteen year old queer-identifying men-divulged personal stories about living at home and feeling like they had to modify appearances in order to appease their families. As interviewee 4 explained, "Culturally my parents have this stereotype of how a male should dress and so living at home still I can't be really creative, I can't wear really over the top things." Interviewee 5 offered a similar story:

“...to be honest I tend to hide certain purchases from my parents since they are super conservative... like especially my more interesting stuff like my fur coat and high platform creepers. I hide them in my closet... My traditional parents still have an influence on me and my clothes, being a student and living at home... Even in my circle of friends, there is major judgment if I step outside their taste preferences and go all out. Like I'd be into putting something cool together with leggings, for example, but I feel a lot of the people close to me would harass me for it. It'd be too feminine."

While not necessarily obliging to all their family's fashion expectations or concerns, some of the older interviewees similarly discussed having tastes that conflicted with their parents; these dress disagreements seemed to have some effect on the men. As Interviewee 15 said: 


\section{DAPPER DUDES}

“... my mom and dad, they just don't get the way that I dress. They'll be like, 'Why did you slick your hair like that? Why did you get a tattoo? Why did you buy a coat in that colour? Do you really think you can find a girlfriend looking like that?'... They are just really set in their ways, but I think a lot of people in that age group are that way... Young people now are just a lot more used to having a whole bunch of different tastes and ideas coming at them all at once..."

These insights suggest a generational divide between old school and contemporary approaches to menswear and masculinity.

Similar to the traditionalist versus young experimentalist dichotomy, Interviewee 6 discussed perceived differences between how residents of small and rural towns approach fashion versus those living in urban environments. Living a considerable distance outside of the city, he explained:

"I would say that where I am living right now I feel partially restricted based on the community that I am in... I don't always totally want to go out and get stared at all day, even though I still usually do because of what I wear regardless... On the flip side if I go to Toronto for the day I will just wear whatever the hell I want because I know that when I go there I am not going to be subjected... I feel like if I lived in a more progressive place I honestly think I wouldn't care as much but I feel like if I wore that in the community that I'm in I might be-probably not like attacked but to some degree people come at me for wearing certain things because of what they are like out there."

While proposing place of residence can either promote or prevent creative personal style, interviewee 6 offered a second important observation. He addressed that not only do men who dress in attire deemed alternative and/or queer face unfavourable criticism, there is also the possibility of danger and violence in extreme cases.

Overall, concerns of unwanted criticisms and disapproval deeply affected, or at least moderately irritated most research participants. They oftentimes discussed how hegemonic appearance ideals are essentially policed by public ridicule. Interviewee 1 pointed out how tiresome these reactions and interactions can be, “ ...the questions I always get are: 'Do you always wear your hair up in a bun? Do you always wear tight 


\section{DAPPER DUDES}

pants? Where do you get all your clothing because it doesn't match?' Yah, it's pretty lame." Additionally, some men noted that while they were comfortable with their gender identity and fashion choices, the general public had the propensity to become uneasy or even adversarial when they wanted to wear gender-blurring or female-targeted garments. As Interviewee 2 said, "I was just at a store and I went to the go try a pair of Rick Owens women's boots and they made a really big issue about it... it's more so the people around me that... feel that there is a certain way for men to dress..." Several other research participants, all queer-identifying men, also spoke about how sales staff and fellow shoppers often made them feel uncomfortable for perusing women's or cosmetics sections. As interviewee 5 explained, "People are still hooked up on divisions in department stores."

\subsection{The Counter-Balancing Act}

Beyond the pragmatic limitations impeding men from buying directional and distinctive high fashion garments (i.e., economic feasibility, fit and sizing issues related to body type, and durability/ versatility of the designs), interviewees additionally suggested fear of judgment influenced fashion choices. Regardless of sexuality, most interviewees admitted that they weren't able to totally let go of their inhibitions when dressing. The interviewees largely expressed a desire to have fun and experiment with statement-making and spirited clothing, while simultaneously maintaining a sense of 'masculinity' or 'manliness.' In this way, it seems as though the men approached fashion with feelings of curiousity and creativity, but also cautiousness. Many of the research participant's sentiments were nicely encapsulated in Interviewee 5 comment, 'I'm totally 


\section{DAPPER DUDES}

down to try on different colours and fabrics and more cutting-edge kind of styles, but... it's a fine line. Like, I don't want people calling me out for overdoing it...” Interviewees vigilantly ensured they did not look overly groomed or too eccentrically dressed. These issues were outlined by Interviewee 6 who noted that masculine dress tended to involve “...a little bit of lack of caring..." while Interviewee 3 echoed that it was important not to "overdress" out of fear of looking “... too loud with your clothes." Offering similar ideas, Interviewee 15 remarked, “...think about the term pretty boy —it has a lot of negative connotations for people. I mean, I am guilty of it myself, like even though I like buying nice clothes and looking good, I will find myself criticizing a guy in my mind if he looks too manicured..."

Upon discussing shopping and dress routines, it was apparent interviewees engaged in a high level of self-reflexivity in an attempt to successfully maneuver through unwritten dress rules and restrictions. As Interviewee 3 disclosed:

"Do I sometimes wonder if I look masculine enough when I'm walking out of my house? Yah, it is totally a question in my mind... Is it as prominent as how long ago did I last wear this? Or does this smell bad? It's not as prominent as those questions are, but it's definitely something that's already in a set of questions in my head... I can truthfully answer that. I don't think a lot of people could... I think a lot of guys like to all believe that their fashion tastes are conveniently whatever is considered masculine, but I think that's bullshit..."

The interviewee's candid admission acknowledges that some men struggle to develop a sense of individual style while feeling constrained by hegemonic masculinity.

Taking into account the conflicting feelings he had about appearance management, Interviewee 19 also frankly spoke about gender expectations:

"To be honest the fashion game is kind of a mind fuck... It's like we're supposed to try hard to look current and like we're up on things... but we're also supposed to act like our whole outfit and look all just kind of came together effortlessly... it's like we all think the cool guy walking down the street just threw his outfit 


\section{DAPPER DUDES}

together instinctually without having to worry about it... I think that's a fallacy... I mean your style should kind of come together naturally, I get that, but it takes effort and it takes maintenance, that's something no guys seems to fess up to."

This admission points to the way Western notions of masculinity collide with contemporary men's fashion ideals creating an impossible situation for male consumers. These concerns were most prominent amongst heterosexual interviewees who felt as though they were paradoxically expected to look good but also not admit to spending considerable time on grooming and dressing routines.

Some research participants discussed "pulling in the reins" and modifying ensembles to make more subdued fashion statements in order to avoid potential mockery or critique. As Interviewer 13 explained, “...sometimes I just don't really want to take the flack, so I ask myself, do I really want people bitching at me today? Well, maybe I'll wear one less piece of colour to chop a couple comments...” Interviewee 9 reiterated a similar point, "Sometimes I think about what I want wear and go, is this too feminine? Maybe I should wear an unzipped hoodie over this graphic t-shirt. I always kind of like to neutralize." Furthermore, some interviewees felt that Canadian culture, devoid of a rich fashion history, was especially stifling when it came to creative dress. As Interviewee 10 said, "I got a bunch of colourful clothes from brands like Kenzo when I was living in Hong Kong.... it doesn’t translate as well back here. I think some of the crazier stuff I got I can't wear back in Canada." These statements indicate that while some men took pleasure in incorporating more playful or whimsical designs into their wardrobe, they documented hesitancy and restraint when styling these pieces. 
DAPPER DUDES

Many of the men seemed to strategically offset elements that might be deemed 'feminine' with 'masculine' dress styles so as to not blatantly oppose masculine ideals. As Interviewee 15 insightfully proposed:

"I was think guys almost counteract looks that might come across as too try hard and manicured with manly elements. It's like when you look at the trend of Brooklyn hipsters in skinny jeans or super tailored suits - the guy always has a burly beard it seems - that's the trend right now. I feel like guys are proving they are manly in a way, and it like helps them balance out the polishedness and puttogetherness of the outfit... I can even admit when I have scruff and have some of my tattoos showing, for whatever reason I feel like I can get away with more (style wise.)"

As the above experiences highlight, while perhaps not always totally conscious of it, interviewees demonstrated that they both accepted and rejected masculine ideals through fashion consumption in a complex way.

\subsection{The Queer Factor}

While homosexual interviewees detailed the invisible barriers that they encountered, they perceived dress codes to be even more rigid for heterosexual men. Many of the queer research participants suggested their straight male counterparts might actually have "repressed" style tendencies, as noted by Interviewee 2. Interviewees 2, 3, 4, 9, 10 and 18, who all identify as homosexual/queer, all suspected that they were afforded more creative freedom then heterosexual men. Interviewees 2 and 4 further strengthened their argument, revealing it wasn't until they 'came out' about their sexual orientation that they felt comfortable participating in fashion. As interviewee 2 explained, "I think as I became more open with myself about my sexuality I also was able to become more open to a realm of possibilities I shut off because I told myself real masculine guys don't get into that sort of thing." 


\section{DAPPER DUDES}

Despite having their own fashion limitations, many of the queer interviewees felt that heterosexual men have an even smaller repertoire of socially appropriate style offerings to choose from. As Interviewee 3 remarked:

"I've had guys compliment my clothes, who are entirely straight, and go 'you look great, where's that from?' And I'll go 'Oh this is a women's top and these are women's pants,' and for some reason the comment that always follows is, 'only you could only pull that off, I could never pull that off.' And it's like, you've never tried to pull it off and you have never ventured into expressing yourself fashion wise in that way because you are so constricted by the idea of what masculinity is and how you should act."

As this example suggests, sexual orientation can still influence what men feel comfortable wearing; masculine standards are complex and contingent on a number of factors including sexuality.

Not all the queer identifying interviewees, however, were comfortable experimenting with women's garments or those with 'feminine' details and colour palettes. Moreover, many of the gay interviewees who did experiment with genderblurring fashion styles revealed that they were careful to ensure their overall look maintained a sense of manliness. For example, Interviewee 5 noted, “...just because you are wearing something that is intended for the female gender, doesn't mean you can't pull it off as man ... feminine garments can actually accentuate your masculine physical qualities... a nice defined body in a silk shirt or sheer fabric can actually highlight that fact through contrast." Overall, the interviewees indicated that heterosexual and homosexual men, alike, are usually mindful of hegemonic masculine aesthetics. In fact, some homosexual men were very vigilant about not looking "too gay.” As Interviewee 11 noted, "I tend to stay clear of the stereotypical gay men's trends... I like to try to distance myself from those kinds of cliché looks, or like the manicured Ken doll gay look.” 


\section{DAPPER DUDES}

Interviewee 1 similarly disclosed, "I think because people always teased 'are you a little girl?' when I was younger I have become really conscious about proving that I'm strong and look strong now." He later added: "I just don't want to come off as vain or vapid, but that's my own insecurity about being just labeled as a gay dude who cares too much about himself and his appearances or is being too feminine."

\subsection{Straight Sartorialists}

As many of heterosexual interviewees noted, it wasn't uncommon for their sexual orientation and/ or aesthetic tastes to be challenged because of their clothing choices. For instance, Interviewee 12 explained that other men would sometimes "throw cheap shots" and homophobic pejoratives due to the fact he wore slim fit clothes on his naturally slender frame. Likewise, Interviewee 13 disclosed, "I've been called gay more times than you can imagine... I kind of almost laugh because the guy calling me gay is probably the most poorly dressed guy in the room... they're too scared to do it themselves..." While interviewees mostly insisted that they were emotionally unaffected by these encounters, they also noted that they had grown accustomed to having to defend both their personal style and their interest in high fashion, or at least ignore criticism.

Interviewees had seemed to develop a defense against those who taunted and teased them, suggesting critics lacked the creative and cultural awareness required to appreciate their fashion choices. Many of the other heterosexual men argued that they simply approached fashion from a more creative and progressive place then those who disapproved. When asked about how his style has been publically received, Interviewee 16 suggested that while most of the people he encountered seemed to accept or even 
DAPPER DUDES

admire his polished look, he also faced considerable criticism. Displaying an adverse reaction to denigrators, the interviewee explained, “....when guys who I don't even know call me gay for dressing nicely, well my friends and I always joke that they are unenlightened philistines... It just feels like such an uneducated view on things..." Similarly suggesting he is perhaps more culturally astute and aware then his critics, Interviewee 15 disclosed:

"I've gotten to the point where I actually feed off of men challenging my sexuality. First off, if you have a clue what it comes to fashion you know that a lot of the best-dressed guys, and all the top designers, they're gay. Like a lot of gay men have very modern and cool fashion tastes so I'm actually pretty comfortable and fine with those kind of jokes. Like, let's be honest I' $d$ rather be mistaken for a cool gay guy, then a boring suburban dad or something."

It is apparent interviewees wished to distance themselves from "ignorant" critics, identifying themselves as creatively inclined city dwellers with a more refined and mature approach to style.

\subsection{The Men's/ Women's Fashion Divide}

Many interviewees felt their sartorial interests were discredited not only as a result of fashion's feminine associations but also because it is largely seen as a lesser creative pursuit then other artistic outlets. The young men acknowledged that even within the field itself, women's fashion was typically considered a more elevated endeavor then men's fashion. While research participants suggested menswear was evolving in a positive direction, they also said that distinctions between the two markets were still very apparent. As Interviewee 12 suggested, “....women still have a lot more flexibility then men when it comes to dress options." 


\section{DAPPER DUDES}

In terms of commercially available and socially acceptable clothing styles, Interviewee 11 pointed out, "Women get to play around a lot more with shapes and silhouettes, like they can wear mini or maxi skirts and cropped or billowy tops... It's fun to play around with proportions and with menswear it's like, how many different lengths can you cuff your jeans at?” Offering a similar observation Interviewee 16 explained, "People still have this perception that menswear is all about sharp tailoring and sticking with one kind of silhouette... in women's wear it feels like there is just more variety..." Interviewee 14 offered additional insight, suggesting that the men's market still predominantly offered a limited variety of dark shades, neutrals and earth tones in terms of available colour palettes. As these observations suggest, it seems there are still certain design constraints that are difficult to overcome.

Unsatisfied with the pedestrian reality of much of the affordable menswear market, some of the interviewees suggested that design uniformity has also resulted in mundane men's street style. As Interviewee 1 observed, “...it seems like every guy is trying to pull off the same thing; it's a whole bunch of men in toques with their Red Wings and wool sweaters on..." Also addressing the homogeneity of much men's fashion, Interviewee 3 explained:

“The reality is still that women's fashion is more focused on then men's fashion. Like the store I work at now, there is a hell of a lot more interesting stuff on the women's side that I'd rather be wearing then the men's side. And a lot of stuff on the guys side is all expensive plaid and denim... The men's product is all stuff that I have seen before, and it's not something I could get away with tricking customers into thinking that this is new, that it is different from what's been spun out countless times before."

This dissatisfaction with available apparel styles was recurrent among many of the men, indicating the Generation Y market is not adequately catered to. 


\section{DAPPER DUDES}

Consistent with Interviewee 1 and 3's suggestions that a limited number of styles are accessible to male shoppers, Interviewees 14, 17 and 19 noted popular men's fashion still largely revolves around functionality and durability. These design tenants leave little room for 'unnecessary' ornamentation or eye-catching additives. Interviewees commonly referenced three fashionable styles they felt to be the most popular and sellable in recent years: a) the sophisticated gentleman aesthetic, b) the utilitarian workwear trend, and c) the urban-inspired athletic look. While one of the popular street styles is steeped deeply in $20^{\text {th }}$ century suiting traditions, the other two are valued for their wearability and ease. These clothing trends suggest hegemonic masculine values continue to permeate much of men's fashion, as practicality remains of primary importance to many consumers.

Interviewees also saw evident differences between genders within the high fashion runway world. As Interviewee 6 expressed:

"With menswear I only ever see it just as clothing... the way that women's wear can be pushed and can be styled and can be created -it becomes something so far beyond that like it is an artwork. Like it is so structured and so built up that it is not just fashion anymore, it's literally a moving sculpture, it's a performance piece.”

Pointing to women's fashion's rich history with Prêt-à-Porter and Couture, Interviewee 19 similarly outlined the creative strengths he considered women's wear to have over menswear. "I feel like people think female bodies are best for playing with unique proportions and shapes... it's a lot less common in fashion design to see really innovative clothes and unusual silhouettes for boxy body shapes or, male bodies in general ..." He went on to mention draping techniques and fabric manipulations that are typically reserved for women's wear. These interviewees noted that the pursuit of beauty, in all its forms, is still largely considered to be a feminine goal. They felt even within the industry 
DAPPER DUDES

there was less excitement and emphasis on creating visually compelling and challenging looks for men.

\section{Men's Fashion Progressions}

Despite the outlined creative limitations, interviewees felt men's fashion was propelling forward and becoming more fluidly defined (as illustrated in 3.1 and 3.2). Some of the more fearless fashion enthusiasts spoke about the ways they subversively played with gender norms, while others blurred gender and sexuality boundaries more subtly — both of which ultimately encourage more dynamic approaches to men's dress (as detailed in 3.3, 3.4 and 3.5). Interviewees suggested men's fashion concerns were magnified due to social media (3.6) and were optimistic menswear would continue to grow as a creative and conceptually worthy pursuit (3.7).

\subsection{New Perspectives on Men's Fashion}

Having dealt with creative restraints when dressing, many interviewees enthusiastically reported that they felt men's fashion was diversifying and becoming more culturally relevant for a broader subset of men. Numerous participants suggested that a growing number of fashion efforts were deviating from traditional menswear aesthetics. For instance, Interviewee 13 explained how he liked being challenged on his tastes and ever-evolving style, “... a lot of guys keep saying fashion is just going to get weirder. I don't think that's a bad thing. I think that it will allow more people to express themselves, potentially more people will fall into different styles that will fit who they are and nicely represent them." Interviewee 6 echoed these ideas, suggesting male 


\section{DAPPER DUDES}

consumers were becoming more open to a broader range of trends. He pointed to the recent widespread popularity of super skinny denim, adopted by men of diverse backgrounds despite their potential homosexual connotations as tight-fitting garments. He went on to suggest fashion was growing as both an industry and creative field, “...menswear has started to push the envelope... I think it is hitting a turning point, offering more then what was available just a few years ago."

Many of the participants suggested they felt male fashion consumer's attitudes were slowly shifting. Offering the perspective of a nineteen-year-old, Interviewee 9 spoke about these changing mentalities, "I think how people perceive fashion is totally dependent on their age.... My parents see fashion as feminine. I guess now, if you're a young person like me, you kind of assume everyone has a slight interest in your peer group.” Interviewee 16 proposed very similar advancements in how men's fashion has been appreciated across time. He noted, "I think my grandfather probably prioritized respectability first and foremost, like he was probably more interested in the time honoured way of dressing...I'd be more into looking for something with a unique or interesting quality to it. I think it's because fashion is more about originality now..." Research participants continually made these affiliations between youth and expressive personal style.

Several interviewees suggested that an increasing number of men are experimenting with unconventional clothing in part because of larger cultural and societal shifts. As Interviewee 14 proposed,

"Men's fashion trends might even be affected by things like gender equality and marriage equality; anti-bullying has become really big in the last few years as well... people are feeling more comfortable with being accepted based on who they are... When you're feeling very comfortable and confident... then you might 


\section{DAPPER DUDES}

be more willing to explore other facets of yourself... you might be more willing to explore art and fashion and other creative things..."

Interviewee 19 reiterated a similar argument, “I think men's fashion today is more about a kind of abstract kind of manliness. It's not this super exact or specific thing. And I think that's something younger kids are becoming more and more willing to accept.” In addition, Interviewee 7 suggested, “...on a deeper level, I think more young guys are being taught it's okay to have a sensitive and creative side..." which he felt would help open men's street style up to become more adventurous and interesting. These men proposed that as those around them would become more accepting of difference, fashion challenges and criticisms would diminish.

\subsection{Reimagining Masculinity}

As style conscious men and avid readers of fashion media, many interviewees pointed out that there was now a multiplicity of ways to enact and display masculinity. As Interviewee 9 said, “...with masculinity it all depends on the context... there is like masculinity on the runway, masculinity in real life, masculinity in gay culture and masculinity in women. There are so many variables." Furthermore, through activity participating in fashion and experimenting with diverse styles of clothing, interviewees seemed to see masculinity as something abstract or in-flux. Interviewee 2 said,

“...people will reference masculine aspects like they did before, but I think now it's kind of free range... one of my really good friends a couple of days ago was in a full-length black skirt and he is a big muscular guy; he still looked super masculine. So yah, I totally think it's kind of an essence or the way people carry themselves." 


\section{DAPPER DUDES}

In this way, while the term 'masculine' was still used as an adjective when discussing men's fashion, interviewees often understood it as nonspecific or subjective and situational.

Many of the interviewees similarly suggested that there is no longer one clear aspirational way for men to dress and act. As Interviewee 15 explained, "I think if you were to ask a bunch of people to conjure up the ideal masculine and good-looking guy, they would all have a slightly different image in their head." Reflecting on the high fashion world, Interviewee 16 added that the high fashion world "... shows such different kinds of ways that a man can look yet still be cool.” And so, if not directly challenging the purposefulness of the term 'masculinity,' it seems that twenty-first century men's fashion can illustrate that there are a diverse number of ways to look desirable as a man.

While many participants still felt constrained and/or gravitated towards clothing they felt was 'manly,' they demonstrated complex understandings of masculinity. As Interviewee 9 stated, "You can't explain masculinity because what might be masculine to me might not be masculine to someone else. It's so subjective..." Interviewee 7 similarly proposed that not all men, especially young queer men, abide by binary gender norms and dress codes. He expressed:

"I think a lot of guys like me are kind of okay with being somewhere in the middle, like not totally macho or fem. A lot of younger gay guys seem to be playing with masculine and feminine clothes at the same time, and I think it's because they naturally embody both those sides, like they aren't totally one or the other so they play with both... The look is a little hard, a little soft, a little punk, a little prep, it's just so all over the place and eclectic, but that's where fashion is headed in general anyways."

These observations indicate that culturally defined notions of gender are transforming, perhaps even destabilizing. 


\section{DAPPER DUDES}

\subsection{Subversive Style}

It is pertinent to note - as the purposive sample of men interviewed represented a wide range of demographic traits and fashion aesthetics - several participants had more 'alternative' and unrestricted fashion styles. These men decidedly chose to disregard, even disrupt hegemonic masculine ideals. A select number of queer-identifying interviewees spoke about the enjoyment they received from approaching gender, sexuality and style as fluid constructs. These men were comfortable confusing and/or deviating from gender binaries more overtly. As Interviewee 7 explained,

"I'm really inspired by Diane Keaton in Annie Hall... She's just so amazing because she wore men's clothing tailored to women, with the slouchy pants and off-kilter vests and ties. I think that kind of relates to me and my aesthetic, with my style and my hair and my fairly soft features... A lot of people joke and say that I dress and look like a lesbian, but I don't mind. I've actually started to kind of play it up. It's weird, but also cool, because people think I dress like a masculine female, but I'm a really a guy."

Citing androgynous female musicians such as Patti Smith as additional sources of style inspiration, it is apparent that the interviewee enjoyed playing with and confusing fixed and naturalized understandings of gender and sexuality by adopting a unique set of style references.

Even more blatantly disregarding conventional masculine ideals, Interviewee 8 explained how he took pleasure in embodying non-specific gender identities,

“... recently I have been kind of trying to portray a really androgynous look, in turn a bunch of people at the bar were a little bit uncertain of my gender... I actually like to encourage that debate around my identity, the confusion around my gender...I just don't like things that are boring or are constrained to a very diminutive idea of masculinity."

These participants reveal that not all men strive to adhere to hegemonic ideals, illustrating that some style setters are interested in articulating individualized and new forms of 
DAPPER DUDES

masculinity while actively denaturalizing societal norms. As explored in the following section, a wider range of men also incorporate garments with 'gender-neutral' or 'feminine' elements into their wardrobe in more nuanced ways, blurring gender binaries more subtly.

\subsection{Gender Blurring}

While the majority of interviewees largely abided by gendered dress rules and expectations, they also observed greater crossover of fashion styles in recent years. As Interviewee 19 suggested,

"I think brands are offering up similar kinds of looks and trends for girls and guys. I think you can see it in the cool couples you see walking down the street... just look at Kenzo or other kind of super sought-after Opening Ceremony kind of brands... they all create very similar collections for men and women... young blog-obsessed kids have all fallen in love with the bright colours and logos."

Interviewees appreciated that many fashion aesthetics and trends popular amongst young people were no longer gender specific, as brands were carrying cohesive messages and styles across men's and women's lines.

Interviewee 15 offered similar comments on popular street style looks, appreciating the fact contemporary trends appeared to be non-gender specific,

“It doesn't feel like there are many distinguishable trends for guys and girls anymore. It seems like recently athletic wear has become a popular look for guys or girls... it's a lot of hi-tech fabrics, baseball caps, and varsity jackets... That seems to be one of the 'it' looks right now... and it doesn't really feel like 'masculine' or 'feminine' in any particular way. Sure some guys might wear the trend with looser fitting clothes then girls... but the effect is pretty much the same."

Other interviewees also brought up contemporary trends and spoke about how they often appeal to young people of all gender identities. For example, Interviewee 15 pointed to 
DAPPER DUDES

the widespread popularity of graphic animal and floral prints to suggest men were becoming more receptive to garments with perceivably 'feminine' details. This growing acceptance of wearing garments inspired by women's wear is interesting as fashion scholar Anne Hollander (1994) has observed that for the first time in centuries men are adopting women's fashion style, instead of the other way around.

Many of the interviewees commented on this blending of male and female fashion trends. For example, Interviewee 16 explained that he liked how many fashionable young couples he admired wore coordinating pieces from designer labels that looked interchangeable. He went on to propose that as men and women bond over shared music, film and art interests, it was logical they were also increasingly connecting over fashion styles and trends they could both participate in. These observations suggest that men and women are not only sharing clothing styles, but are inspired by similar aspirational lifestyle goals.

\subsection{The Death of the 'Metrosexual'}

As participants felt as though a growing number of young heterosexual men were openly taking part in fashion, they suggested gay/straight fashion distinctions were blurring. As Interviewee 1 observed:

"... when you look at the term metrosexual.... what does that even mean now? Nobody throws it around anymore, the term died... now every guy with standards wants to look good, it's not some niche category of men... I don't think being straight, gay, or into fashion has anything to do with each other anymore..."

Research participants suggested many heterosexual men were becoming more comfortable purchasing and wearing colourful, graphic, and/or form-fitting designs, stereotypically affiliated with homosexual men. 
Beyond suggesting many heterosexual men have opened up to a broader range of fashionable aesthetics, participants also attributed potential sexual orientation confusion to the fact many young gay men were less connected to traditional gay tropes, making them less identifiable. Interviewee 11, pointed out the 'muscular clone' and 'flamboyant queen' polarities typically associated with gay men of older generations had become outdated, suggesting that gay aesthetics have become less apparent or unified. These observations relate to Nardi's work on Gay Masculinities (2000), as gay men enact a multiplicity of ways of 'doing' masculinity, expressing stereotypical masculinity and less dominant forms in complex ways. While some participants felt it was important that their clothes provided visual clues of their sexual orientation, many others suggested stereotypical ways of dressing for both heterosexual/ homosexual, male/ female binaries were blurring.

Many interviewees acknowledged that men's fashion could grow in a richer, more creative direction through borrowing concepts and designs from women's wear and/or queer adopted dress styles. Interviewee 5 spelled these ideas out in clear terms,

"The thing is, why not borrow trends from girls? Like, I'm not that tall, so why not wear platform shoes if it makes me feel better?... Also, men have been cramming their wallets and keys and things in their jackets and back jean pockets for forever, like why shouldn't they be allowed to carry a fashionable bag?"

Perhaps because these young men have begun to enjoy engaging with and wearing designs with conventionally 'feminine' elements, they have also begun to question the purposefulness of male/female dress distinctions. 
DAPPER DUDES

\subsection{Social Media and Selfie Culture}

When asked to reflect on changes in contemporary fashion, Interviewees 2, 5, 9, $10,11,13,14,17$ and 19 all brought up social media; they spoke about how instrumental they felt it was in stimulating interest in men's fashion. Research participants proposed that digital technologies and online networks influence men's style in two ways: Firstly, they allow young men access to diverse sources of style inspiration, which some interviewees said encouraged them to make increasingly creative and bold sartorial statements. Secondly, they pressure males to focus more closely on their appearances. And so, while many interviewees felt freer to openly express an interest in fashion, they suggested correspondingly that those who were apathetic might feel a greater sense of expectation to focus on their physical and visual selves.

Reflecting on the positive consequences of social networks and the fashion blogosphere, Interviewee 5 suggested, “ I think the Internet has encouraged a lot of people to try things they never thought they would. Going online they get to look at a lot of different fashion styles they might not otherwise see or hear about and that might give them the confidence to try them." With the explosion of fashion forums, web pages, and online networks like Lookbook.nu, amongst other social media and Internet initiatives, how and where interviewees looked for inspiration was said to be evolving. Participants suggested social media sites have made it possible for fashionable young people to connect virtually and establish themselves and their aesthetic. Additionally, as Interviewee 9 explained, these outlets have also offered up a venue for emerging vanguard designers and unconventionally stylish men to receive attention and notoriety 


\section{DAPPER DUDES}

outside of traditional print publications. Interviewees felt like they could reach out to likeminded consumers from diverse backgrounds and continue to grow stylistically.

Beyond opening them up to a kaleidoscope of men's style inspirations and offerings from across the globe, interviewees emphasized that social media like Instagram seemed to heighten the importance their peer groups placed on fashion and physical presentation. As Interviewee 2 insightfully explained, "... because we have become so into social media and visual culture, I think fashion will become even more important for young people, guys included...we live in this insane image-obsessed digital age where we are all super linked in and I think thanks to that world, guys will be more and more interested in how they should present themselves... Even when you look on comments on sites like Facebook it's so often, you know, 'looking good buddy,' or 'that shirt is awesome,' it's like that's what guys are being evaluated on more now."

As social media are utilized by youth to establish and maintain a sense of self (WilkcoxUgurlu, 2011), Interviewee 2's observations are compelling as they point to the fact that this identity-building process is largely visual, based off of the personal images one chooses to strategy display through their digital profiles and accounts.

Interviewees suggested they felt a pressure to carefully "curate" virtual identities; they suggested social networking sites have made it evermore important to attain a desirable look and personae. As Interviewee 5 said,

"It's all about taking selfies and street style photos of you and your friends now. I always joke with my friends life is about 'likes'... I think the rise of a social media selfie culture puts pressure on a lot of young guys to have a specific image that they show off, and, having a cool personal style is a big part of that. It's part of this larger package you're selling... like, look where I'm travelling to, look where I'm having dinner, look who I'm hanging out with, and look what I'm wearing." As indicated, linkages between fashion, social media and identity appear to be growing increasingly interconnected." 
DAPPER DUDES

And so, young male identity appears to be increasingly wrapped up in one's physical appearance and dress choices - these aesthetic elements play an integral role in defining one's creative interests and assist young people in aligning with neo-tribal networks that form ephemerally on social media.

\subsection{The Opportunity for Artful Fashion}

Overall, interviewees believed in the creative and cultural worth of men's fashion. They hoped to disprove denigrated ideas that they felt many people had about fashion being a vacuous, trivial leisure activity. In terms of a hierarchy amongst creative fields, several men noted men's fashion is often culturally perceived to be at the bottom of the list. They wanted to challenge those associations and felt aligning with other creative and artistic pursuits would help bolster fashion's cachet and credibility. For instance, Interviewee 19 suggested fashion could be the catalyst for interdisciplinary creative output: "I think you can totally blend fashion, art, music and other creative ingredients together... just look at cool menswear runway shows or fashion films.... I like when they incorporate emerging musicians and DJs or cool directors and videographers into the $\operatorname{mix} . .$.

Some participants explained that they were excited by the idea of fashion existing amongst an mélange of other creative outlets. For instance, interviewees suggested that they liked men's fashion and lifestyle magazines because they helped build linkages between fashion and other creative forms. As one example, Interviewee 8 suggested his favourite magazine Dazed and Confused because he felt it traversed various art forms including fashion, film, music, graphic design and photography, pointing to the ways they 


\section{DAPPER DUDES}

intertwine and relate to one another. In this way, interviewees expressed an interest in finding brand identities they could relate to and appreciated menswear initiatives with connections to larger artistic communities and practices. Interviewee 16 pointed to the success of men's fashion label Supreme as an interesting example. He suggested the brand was highly sought after because he felt like it was an authentic part of New York City culture, having been adopted by both local skateboard and hip-hop circles. And so, beyond 'feminine' concerns of physical attractiveness, interviewees were eager to support menswear labels they felt were a part of cultural movements, city identities, and music scenes.

Many participants were hungry for clothes they felt had 'substance' and meaning beyond their visual 'surface level' appeal. Some men articulated that because the industry is considered feminine and creatively lesser, they appreciated fashion collections and media content that challenged those ideas and had a definitive vision and intent. As Interviewee 6 stated,

"I'm looking for styles or designs that kind of go beyond just basic fashion, like it's trying to do something more then just be clothing. It's trying to be a statement, it's trying to be a movement, it's trying to be a turning point in what we consider to be fashion, what we consider to be wearable and what we consider to be cool. Like I'm looking for something that's more then just the regular, mediocre thing that's out there. I want to pick up a magazine and I want to look at fashion that really intrigues me and makes me want to know more about what the designer is doing and what they are trying to create and get across." Moreover, many of the young men said that they appreciated menswear labels

with specific intentions and artistic visions. Interviewee 19 noted, “... I like it when they give you a little back history about a brand or a designer, or maybe mention the creative process behind interesting design details... " As a knowledgeable fashion consumer he explained that he appreciated when fashion companies didn't "underestimate" the 


\section{DAPPER DUDES}

intelligence of male customers, firstly by creating interesting and innovate menswear and secondly by effectively communicating the uniqueness of those designers. Interviewee 17 reiterated these ideas, "I kind of like where fashion is going, it seems to becoming more focused on substance and more concern about the social end of it, like where it's being made and how it's being made." As these comments indicate, interviewees were eager to explain that their interest in fashion was about more then simply projecting something superficial about their appearances and/or affluence; they wished to align with menswear labels they felt shared those deeper values.

In the realm of high fashion, many participants suggested that there were excited by the growing number of menswear shows with thoughtful and directional menswear motifs and runway themes. They suggested that future fashion visionaries will likely push men's apparel in increasingly more creative and conceptually strong directions, even challenging the boundaries and definitions of 'men's fashion' altogether. The interviewees often spoke about their favourite designers and how they felt they were elevating men's fashion as a field. For example, Interviewee 2 spoke about the way Yohji Yamamoto “... combines really challenging shapes and design concepts together.” Relatedly, Interviewee 11 suggested, "We need more designers like JW Anderson who have artistic kind of ideas going on who encourage intelligent dialogue - they are the ones that can help bring menswear to the next level." He went on to explain that he appreciated how emerging designers were framing male models as effervescently beautiful with “...the dewy skin, the sculpted hairdos and the super skinny bodies..." He argued, "I feel like fashion is kind of all about constantly reinterpreting beauty, so why not apply it a man? It's almost like a new frontier." 


\section{DAPPER DUDES}

Furthermore, while numerous interviewees suggested women's fashion has 'gone further' creatively, some also asserted that there was an opportunity for the menswear category to progress and provoke. Arguing that there was still unexplored ground in men's fashion, Interviewee 2 observed,

“... it's hard to find a concept that hasn't been done over and over again in women's wear. With men's fashion, though, it seems like a lot of designers have continually shown the same stuff, and the same tailored suits... there are a lot more stones unturned in terms of the kinds of themes a men's designer can use."

And so, while acknowledging that that women's fashion industry potentially has a richer and more robust history, interviewees felt that only meant the women's marketplace and high fashion runway scene was more saturated - leaving more conceptual and creative room for menswear to grow.

Ultimately, many research participants longed for a future where fashion is less defined by gender or sexuality and is more focused on one's lifestyle and creative interests. As Interviewee 6 expressed,

"I definitely hope that men's fashion keeps becoming more expressive and it keeps opening up to the fact that there all these different lifestyles that different people lead and that each one has it's own image and aesthetic to it. Ultimately fashion can be open to each and every lifestyle that is out there and it shouldn't be close-minded so that anyone and everyone can dress however the hell they want. And like that's where I would like it to go."

These men hoped to see men's fashion grow in an ever-increasing number of diverse directions, catching up to women's fashion and becoming just as open to personal style experimentation and exploration. 
DAPPER DUDES

\section{Discussion}

Upon compiling research findings and assessing the interviewees' attitudes and approaches to fashion, it appears as though young men today are increasingly inclined to see fashion as a means of creatively expressing themselves and establishing their personal identity. While men's style is still often thought to be as a surface level pursuit - based predominantly on outshining peers and attracting sexual or romantic attention (Sender, 2006) - this research suggests there are often deeper intentions and implications behind sartorial choices. This was made evident by the interviewees who were eager to articulate that their fashionable looks were not just a 'cool' façade, but an authentic extension of their larger lifestyle choices and sense of self. When interviewees were challenged to reflect on their stylistic preferences, they often touched on rich layers of meaning embedded in their personal style. In this way, it seems contemporary men's fashion has moved beyond the rhetoric of the 1980 s new man and early 2000 s metrosexual. These consumer approaches positioned fashion as an acceptable aid for men to achieve and express hegemonic masculine goals, mainly related to money, sex, and power (Sender, 2006). As the fashion field continues to develop, a growing range of young consumers, style content, and clothing are celebrating a more meaningful articulation of menswear. Young men today are increasingly focused on establishing individuality, creativity, and connectivity through physical presentation.

As Edwards (2006) has asserted, men's fashion is a contradictory space. It is important that research acknowledges the paradoxes inherent in the research results. For instance, findings observed that interviewees' personal styles were often restrained out of 


\section{DAPPER DUDES}

concern of homophobic criticism, while later suggesting binary homosexual/heterosexual dress distinctions were blurring. Findings also indicated that interviewees often felt uncomfortable experimenting with conventionally 'feminine' clothing styles, while later suggesting fashion-forward men and women, alike, were beginning to gravitate towards similar fashion aesthetics and lifestyles that lacked gender specificity. In this way there is a clear tension at play. As Ervin (2011) has observed through her research on the metrosexual, fashion trends that deviate from hegemonic masculine ideals are often met with backlash and renunciation, meaning the path to greater fashion expression is not easy or straightforward.

While participants were still influenced by traditional masculine dress conventions, they also believed that there was no longer a singular or 'right' way to look and dress like a man. These young males saw fashion as a place where they could express themselves as unique beings through assembling a range of fashion styles and signifiers. In attempting to be idiosyncratic, interviewees inadvertently and/or intentionally departed from hegemonic masculine dress codes in one form or another. In this way, young male fashion consumers are both influenced by conceptions of 'masculinity' and have the ability to shift or subvert the way it is culturally understood and defined. As Forth (2008) has observed, hegemonic masculinity is continually disrupted as well as validated. Malossi has identified similar trends across the men's fashion landscape, noting, “... the rigidity and strict codification that were once characteristic of male identity, and which were "depicted" in men's fashion, have been outmoded, discarded to make way for the

possibility of a far more nuanced, complex, and diversified range of variants on possible identities. This, in turn, translates into a far greater array of possible forms of 


\section{DAPPER DUDES}

consumption... a unified male identity was replaced by a manifold identity, wardrobes (have) multiplied to match each of the possible new identities" (2000, p 30). As men's fashion seems to be diversifying — as indicated by the broad range of styles observable across participants - masculine ideals seem to be fracturing, becoming less singular and specific.

It seems that the expansive network of tastemakers and trendsetters that make up the menswear industry present consumers with conflicting conceptions of masculinity and inadvertently illustrate that there are a multitude of dress aesthetics to aspire to. While the market has opened up to an expansive range of offerings, critics have suggested this is potentially less about freedom of creative expression and more about generating capital and furthering the neoliberal project (Sender, 2006). A cynical explanation for "the metamorphosis of the male" is that "... the image of uniform, unnuanced virility is just not as profitable as is its opposite... the more nuances of identity there are, the more possibilities there are for desire to be generated or stimulated, the more suits, outfits, and accessories can be sold" (Malossi, 2000, p. 29- 30). Regardless of industry intentions - if not directly challenging the purposefulness of the term 'masculinity' - twenty-first century men's fashion can at least illustrate that there are a seemingly endless numbers of socially and culturally defined 'masculinities' that exist.

As many research participants suggested they were excited by menswear's creative and conceptual potential — findings challenge assertions that young middle-class men largely look towards 'masculine' values like affordability and practicality when consuming clothing, as argued by Galilee (2002). Taking these observations into 


\section{DAPPER DUDES}

consideration —as fashion conscious interviewees were purposively sampled — future research on a broader subset of men would provide insight into larger societal attitudes. Ultimately, findings more closely align with Bakewell, Mitchell and Rothwell's 2006 study suggesting Generation Y men possess different attitudes to fashion then older age cohorts. In line with Edwards' (2011) work, these researchers suggest increases in male appearance consciousness are influenced by the proliferation of men's magazines, the establishment of sportsmen as fashion spokespeople, the pluralism of masculinity through multiculturalism, and the changing perceptions of the LGBT community, amongst a variety of other factors (Bakewell, Mitchell \& Rothwell, 2006).

This research suggests social networking sites are an additional cause for contemporary male interests in dress and physical display. Patterson and Elliott's 2002 suggestion that the male gaze has been inverted seems to be magnified under these new conditions, as social media has led men to increasingly scrutinize their fashion choices and physical bodies. And so, the ramifications of a more fashion conscious male consumer are wide and varied: just as fashion's power has had both positive and negative influences on women, so too will it increasingly affect men in adverse ways. Positively, it appears the burgeoning menswear industry has the potential to open men up to new forms of creative expression through conceptual experimentation and visual exploration. Conversely, it also is likely to heighten individual male insecurities, as idealized yet often unattainable designer brands and body types become of growing importance.

Overall, the interconnected relationship between a) fashion and physical presentation, b) social media, and c) musically driven neo-tribal networks are fundamental in establishing and expressing young male identity. These influences come 
DAPPER DUDES

together to "create coherent identity narratives" (Wilcox-Ugurlu, 2011). Because one's sense of identity and individuality is difficult to articulate and exists in an invisible and unstable way, it is little wonder people "curate" collections of material things, within aesthetic and taste categories, to help mark who they are. And so, one of the key young male motivations for being interested in fashion is the engrained desire to connect, belong, and assert one's position as a member of desirable tribal networks and communities.

\section{Future Research Opportunities:}

As research focuses on a specific young Canadian demographic, it would be beneficial to expand the scope of this research. It would be fruitful for future studies to further explore the role of 'place of residence' and further unpack whether men face different opportunities and challenges when establishing a sense of style in rural and urban environments. Similarly, it would enrich existing research to complete additional investigations of non-Western male fashion consumers and their attitudes towards masculinity. For instance, it would be of interest to comparatively explore how masculinity is understood in China, where men now spend more on luxury goods then their female counterparts (Chevalier \& Lu, 2010). Moreover, it would be valuable to continue to explore whether Generation Y males will maintain their fashion interests and openness to vibrant styles as they age. 
DAPPER DUDES

\section{Industry Implications:}

This study postulates that as a growing number of men develop stronger relationships with fashion and style, they will be looking for increasingly artful and creatively meaningful qualities in their clothes. Overall, interviewees appreciated fashion for much more then the physical garments-they were drawn in by it associations with larger lifestyles, creative endeavours and ideas. To reach young male consumers, it is important that marketers tap into these facets, connecting with larger creative and cultural networks. Findings concur with Edwards (2006) observation that men's and women's consumption patterns have become more closely related due to some blurring of gender and sexuality boundaries in fashion. Psychographic matters seem to have taken precedence over demographic matters (Edwards, 2006), as interviewees suggested they were more concerned about using their clothing to express particular attitudes, personalities and lifestyles, then they were about displaying class, gender or sexual orientation.

\section{Conclusion:}

Ultimately, this ever-increasing focus on men's fashion allows consumers to understand gender binaries and masculinity boundaries more fluidly. Research postulates that young men will continue to become less interested in displaying gender and sexuality markers through their clothing, as their primarily focus becomes identifying with idealized lifestyles and likeminded young creative groups. These observations align with existing research on consumer culture, fashion and identity (Featherstone, 1987; 2007) broader shopping and lifestyle choices come together to help form one's sense of self. In 


\section{DAPPER DUDES}

conclusion, while style and self-presentation are still primary means of establishing identity categories such as gender and sexuality, these identity-building techniques can also be used to confuse or challenge the parameters of such classifications, ideally leading to more inclusive understandings of masculinity and men's fashion. 
DAPPER DUDES

Appendix A

Participant Sample Information

\begin{tabular}{|c|c|c|c|c|c|c|}
\hline Pseudonym & Age & Occupation & $\begin{array}{l}\text { Sexual } \\
\text { Orientation }\end{array}$ & $\begin{array}{l}\text { Race/ } \\
\text { Ethnicity }\end{array}$ & $\begin{array}{l}\text { Magazines } \\
\text { Read/ Yr }\end{array}$ & $\begin{array}{l}\text { Blogs Read/ } \\
\text { Month }\end{array}$ \\
\hline Interviewee 1 & 24 & $\begin{array}{l}\text { Dancer/ } \\
\text { Physical } \\
\text { Trainer }\end{array}$ & $\begin{array}{l}\text { Homosexual/ } \\
\text { Queer }\end{array}$ & $\begin{array}{l}\text { Caucasian/ } \\
\text { East Asian }\end{array}$ & $\begin{array}{l}21 \text { and } \\
\text { over }\end{array}$ & $6-10$ \\
\hline Interviewee 2 & 24 & $\begin{array}{l}\text { Brand } \\
\text { Manager }\end{array}$ & $\begin{array}{l}\text { Homosexual/ } \\
\text { Queer }\end{array}$ & Caucasian & $16-20$ & $1-5$ \\
\hline Interviewee 3 & 20 & $\begin{array}{l}\text { Stylist } \\
\text { Consultant }\end{array}$ & $\begin{array}{l}\text { Homosexual/ } \\
\text { Queer }\end{array}$ & $\begin{array}{l}\text { Black/ } \\
\text { Fijian/ } \\
\text { Japanese/ } \\
\text { Native }\end{array}$ & $1-5$ & $1-5$ \\
\hline Interviewee 4 & 19 & $\begin{array}{l}\text { Graphic } \\
\text { Design } \\
\text { Student }\end{array}$ & $\begin{array}{l}\text { Homosexual/ } \\
\text { Queer }\end{array}$ & Latino & $1-5$ & 21 and over \\
\hline Interviewee 5 & 19 & $\begin{array}{l}\text { Art student/ } \\
\text { Dancer/ Sales } \\
\text { Associate }\end{array}$ & $\begin{array}{l}\text { Homosexual/ } \\
\text { Queer }\end{array}$ & Caucasian & $\begin{array}{l}21 \text { and } \\
\text { over }\end{array}$ & 21 and over \\
\hline Interviewee 6 & 21 & $\begin{array}{l}\text { Graphic } \\
\text { Designer }\end{array}$ & $\begin{array}{l}\text { Homosexual/ } \\
\text { Queer }\end{array}$ & Caucasian & $6-10$ & $1-5$ \\
\hline Interviewee 7 & 19 & $\begin{array}{l}\text { Fashion } \\
\text { Design } \\
\text { Student } \\
\end{array}$ & $\begin{array}{l}\text { Homosexual/ } \\
\text { Queer }\end{array}$ & Latino & $6-10$ & $16-20$ \\
\hline Interviewee 8 & 24 & $\begin{array}{l}\text { Artist/ Works } \\
\text { at Coffee } \\
\text { Shop }\end{array}$ & $\begin{array}{l}\text { Homosexual/ } \\
\text { Queer }\end{array}$ & Caucasian & $1-5$ & $6-10$ \\
\hline Interviewee 9 & 19 & $\begin{array}{l}\text { Humanities } \\
\text { Student }\end{array}$ & $\begin{array}{l}\text { Homosexual/ } \\
\text { Queer }\end{array}$ & Caucasian & $1-5$ & 21 and over \\
\hline Interviewee 10 & 24 & Lawyer & $\begin{array}{l}\text { Homosexual/ } \\
\text { Queer }\end{array}$ & Caucasian & $1-5$ & $1-5$ \\
\hline Interviewee 11 & 23 & $\begin{array}{l}\text { Social } \\
\text { Science } \\
\text { Student } \\
\end{array}$ & $\begin{array}{l}\text { Homosexual/ } \\
\text { Queer }\end{array}$ & Caucasian & $\begin{array}{l}21 \text { and } \\
\text { over }\end{array}$ & $6-10$ \\
\hline Interviewee 12 & 29 & $\begin{array}{l}\text { Portfolio } \\
\text { Analysis } \\
\text { (Finance) } \\
\end{array}$ & Heterosexual & Caucasian & $1-5$ & $1-5$ \\
\hline Interviewee 13 & 27 & $\begin{array}{l}\text { Mortgage } \\
\text { Broker }\end{array}$ & Heterosexual & Caucasian & $1-5$ & 21 and over \\
\hline Interviewee 14 & 25 & $\begin{array}{l}\text { Blogger/ } \\
\text { Lifestyle } \\
\text { Editor } \\
\end{array}$ & Heterosexual & East Asian & $\begin{array}{l}21 \text { and } \\
\text { over }\end{array}$ & 21 and over \\
\hline Interviewee 15 & 29 & $\begin{array}{l}\text { Advertising/ } \\
\text { Marketing }\end{array}$ & Heterosexual & $\begin{array}{l}\text { Caucasian/ } \\
\text { East Asian }\end{array}$ & $1-5$ & $1-5$ \\
\hline
\end{tabular}


DAPPER DUDES

\begin{tabular}{|l|l|l|l|l|l|l|}
\hline Interviewee 16 & 27 & $\begin{array}{l}\text { Med School } \\
\text { Student }\end{array}$ & Heterosexual & Caucasian & $1-5$ & $1-5$ \\
\hline Interviewee 17 & 29 & $\begin{array}{l}\text { Shipper/ } \\
\text { Receiver }\end{array}$ & Heterosexual & Caucasian & $1-5$ & $6-10$ \\
\hline Interviewee 18 & 25 & $\begin{array}{l}\text { Senior } \\
\text { Designer/ } \\
\text { Social Media }\end{array}$ & $\begin{array}{l}\text { Homosexual/ } \\
\text { Queer }\end{array}$ & $\begin{array}{l}\text { African- } \\
\text { Canadian }\end{array}$ & $\begin{array}{l}21 \text { and } \\
\text { over }\end{array}$ & 21 and over \\
\hline Interviewee 19 & 25 & $\begin{array}{l}\text { Jr Marketing } \\
\text { Coordinator }\end{array}$ & Heterosexual & East Asian & $1-5$ & 21 and over \\
\hline Interviewee 20 & 26 & $\begin{array}{l}\text { Copy Editor/ } \\
\text { Writer }\end{array}$ & Heterosexual & Caucasian & $1-5$ & $1-5$ \\
\hline
\end{tabular}


DAPPER DUDES

\section{References}

Arnold, R. (2001). Fashion, desire and anxiety. Rutgers University Press: New Jersey.

Bakewell, C., Mitchell, V. Rothwell, M. (2006). UK Generation Y male fashion consciousness. Journal of Fashion Marketing and Management, 10(2), 169-180.

Bancroft, A. (2011b). Leigh Bowery: Queer in fashion, queer in art. Sexualities, 15(1), 68-79.

Bancroft, A. (2012). Fashion and Psychoanalysis: Styling the Self. New York: I.B. Taurus \& Co Ltd.

Bancroft, A. (2013, March 14.) How fashion is queer. The Quoch. Retrieved November 12, 2013, from http://theqouch.com/2013/03/14/how-fashion-is-queer/

Barthes, R. (2006). The Language of Fashion. (Trans. Andy Stafford). Berg: New York.

Bennett, A. (1999). Subcultures or neo-tribes? Rethinking the relationship between youth, style and musical taste. Sociology, 33(3), 599-617.

Breward, C. (1999). The Hidden Consumer: Masculinities, Fashion and City Life in 1860-1914. Manchester: Manchester University Press.

Buchbinder, D. (2013). Studying Men and Masculinities. New York: Routledge.

Butler, J. (1990). Gender Trouble: Feminism and the Subversion of Identity. New York: Routledge.

Carreño, A. (2014). Marc in skirts. In Critical Studies in Men's Fashion, 1(1), 59-68.

Chevalier, M., \& Lu, P. X. (2010). Luxury China: Market opportunities and potential. Singapore: John Wiley \& Sons.

Connell, R. W. (2005), Masculinities, 2nd edition, Berkeley, CA: University of California 


\section{DAPPER DUDES}

Press.

Connell, R. W. \& J. W. Messerschmidt. (2005). Hegemonic masculinity: Rethinking the concept. Gender and Society, 19(6), 829-859.

Craik, J. (1993). Face of fashion: Cultural studies in fashion. New York: Routledge.

Creswell, J. W. (2007), Qualitative Inquiry and Research Design: Choosing Among Five Approaches, Thousand Oaks, CA: Sage.

Crewe, B. (2003). Representing Men: Cultural Production and Producers in the Men's Magazine Market. New York: Berg.

Davies, H. (2008). Modern Menswear. London: Laurence King Publishing Ltd.

Duboff, J. (2014). Meet the ‘yummy': The young, urban male. Vanity Fair. Retrieved from http://www.vanityfair.com/online/daily/2014/03/yummy-young-urban-male

Edwards, T. (2006). Cultures of masculinity. New York City: Routledge.

Edwards, T. (1997). Men in the mirror: Men's fashion, masculinity and consumer society. London: Cassell.

Edwards, T. (2011). The clothes maketh the man: Masculinity, the suit and men's fashion. In T. Edwards (Ed.) Fashion in focus: Concepts, practices and politics(pp. 41- 64). New York City: Routledge.

Entwistle, J. (2000). The Fashioned Body: Fashion, Dress and Modern Social Theory. Polity Press: Cambridge.

Ervin, M. (2011). The might of the metrosexual: How a mere marketing tool challenges hegemonic masculinity. In Performing American Masculinities: The $21^{\text {st }}$-Century Man in Popular Culture. Watson, E., \& Shaw, M. (Eds.) 58-75. 


\section{DAPPER DUDES}

Featherstone, M. (2007). Consumer Culture and Postmodernism. Los Angeles: Sage Publications.

Featherstone, M. (1987). Lifestyle and consumer culture. In Theory, Culture \& Society, $4(1), 55-70$.

Flugel, J. (1930). The Psychology of Clothes. New York: International Universities Press.

Galilee, J. (2002), 'Class consumption: understanding middle-class young men and their fashion choices', Men and Masculinities, 5: 1, pp. 32-52.

Green, D.N. (2009). Somewhere in Between: Transformative Spaces, Shifting Masculinities, and Community Style. University of California: Dissertation.

Hollander, A. (1994). Sex and suits: The Evolution of Modern Dress. New York City: Aldred A. Knopf Inc.

Kawamura, Y. (2011). Doing research in fashion and dress: An introduction to qualitative analysis. New York: Berg.

Kimmel, M.S. (1994). Masculinity as homophobia: Fear, shame and silence in the construction of gender identity. In Brod, H., \& Kaufman, M (Eds), Theorising Masculinities, Newbury Park, CA: Sage Publications.

Kimmel, A. J., \& Tissier-Desbordes, E. (1999). Males, masculinity and consumption: An exploratory investigation. In European Advances in Consumer Research, 4(1), $243-251$.

Kirby, V. (2006). Judith Butler: Live Theory. London: Continuum International Publishing Group. 


\section{DAPPER DUDES}

Kuzel, A.J. (1992). Sampling in qualitative inquiry. In B.F. Crabtree \& W.L. Miller (Eds.) Doing qualitative research (31-44) Research Methods for Primary Care Series, Vol. 3. Newbury Park, CA: Sage.

Logan, N. (2000). Myths and Legends. In Ray Petri: Buffalo. Lorenz, Mitzi. (Ed.) New York: Powerhouse Books.

Luciano, L. (2011). Looking Good: Male Body Image in Modern America. New York: Hill and Wang.

Malossi, G. (2000). Material Man. In Material man: Masculinity, sexuality, style, ed. Gianno Malossi, 24-33. New York: Harry N. Abrams.

Matthews, K., Hancock, J.H, \& Gu, Z. (2013). Rebranding American men's heritage fashions through the use of visual merchandising, symbolic props and masculine iconic memes historically found in popular culture. In Critical Studies in Men's Fashion, 1(1), 39-58.

Miles, M. B. and Huberman, M. A. (1994), Qualitative Data Analysis, 2nd Edition, Thousand Oaks, CA: Sage.

Mort, F. (1996). Cultures of Consumption: Masculinites and Social Space in Late Twentieth-Century Britain. London: Routledge.

Nardi, P. (Ed.). (2000). Gay Masculinities. Thousand Oaks, Calif: Sage.

Negrin, L. (2008). Appearance and Identity: Fashioning the Body in Postmodernity. Palgrave Macmillan: New York.

Paoletti, Jo B., and Brush Kidwell, C. (1989). Conclusion. In Men and women: Dressing the part. Brush Kidwell, C., \& Steele, V. (eds.) 158- 161. Smithsonian Institution Press: Washington. 


\section{DAPPER DUDES}

Patterson, M., \& Elliott, R. (2002). Negotiating masculinities: Advertising and the inversion of the male gaze. In Consumption Markets \& Culture, 5(1), 231-46.

Polhemus, T. (2000). The Invisible Man. In Material man: Masculinity, sexuality, style, Malossi, G. (ed). 44-51. New York: Harry N. Abrams.

Rees, A. (2012, September 11). Luxury Men's Fashion Estimated to Be Growing Twice As Fast As Women's. The Cut. Retrieved from http://nymag.com/thecut/2011/12/mens-fashion-growing-twice-as-fast-aswomens.html

Salih, S. (2004). Variations on Sex and Gender: Beauvoir, Wittig, Foucault (1987) in The Judith Butler Reader. Butler, J., Salih, S, (Eds), 21-38.

Sender, K. (2006). Queens for a Day: Queer Eye for the Straight Guy and the Neoliberal Project. In Critical Studies in Media Communication, 23(2), 131-151.

Stock, K. (2014, March 25). Luxury brands are targeting global yummies: Young urban males. Business Week. Retrieved from http://www.businessweek.com/articles/2014-03-25/luxury-fashion-brandstargeting-global-yummies-young-urban-males

Young, R. (2012). Online appeals to the male of the species. New York Times. Retrieved from http:/www.nytimes.com/2012/06/25/fashion/online-helps-increase-mens$\% 09$ wear-sales.html?_r=0

Wilcox-Ugurlu, C. (2011). Social Media, Existence, Identity Dynamics and Experiential Consumption. Kingston: University of Rhode Island. 